\title{
Os Problemas Epistemológicos da Realidade, da Compreensibilidade e da Causalidade na Teoria Quântica*
}

\author{
Epistemological Problems of the Reality, Comprehensibility and Causality in Quantum Theory \\ Jenner Barretto Bastos Filho \\ Departamento de Física, Centro de Ciências Exatas e Naturais, \\ Universidade Federal de Alagoas, Cidade Universitária CEP 57072-970 \\ Maceió, Alagoas, Brasil; jenner@fis.ufal.br
}

Recebido em 19 de dezembro, 2002. Aceito em 25 de abril, 2003.

\begin{abstract}
No presente trabalho apresentamos uma discussão epistemológica sobre os problemas da Realidade, da Compreensibilidade e da Causalidade no contexto de algumas das questões suscitadas pela teoria quântica, discussão essa que se reflete também num combate à concepção positivista de ciência. Argumentamos em prol de uma maior aproximação entre a epistemologia complexa de Bachelard, a filosofia popperiana do racionalismo crítico e a concepção lakatosiana de programas científicos de pesquisa. Argumentamos, outrossim, em prol de ambas: da necessidade de se levar mais a sério a complexidade do diálogo teoria/experimento e da cautela redobrada em relação à idéia de 'experimentos cruciais' notadamente quando esses são lidos tanto na ótica do positivismo quanto na do realismo ingênuo.
\end{abstract}

We present an epistemological discussion on the problems of Reality, Comprehensibility and Causality in the context of some questions of quantum mechanics. This study also constitutes a struggle against the positivistic conception of science. We argue in favour of a more close connection among Bachelardian epistemology of complexity, Popperian philosophy of critical rationalism and the Lakatosian conception of scientific research programmes. We argue too in favour of the necessity in conceiving the complexities and subtleties of the dialogue theory/experiment and a special attention with respect to the idea of 'crucial experiment'.

Contradiction est une mauvaise marque de verité: plusieurs choses certaines sont contredites; plusieurs fausses passent sans contradiction. Ni la contradiction n'est marque de fausseté, ni l'incontradiction n'est marque de vérité. (Pascal, Pensées, Art. VI, n. 384) ${ }^{1}$

\section{Introdução}

Os problemas epistemológicos suscitados pela teoria quântica são tantos e tão profundos que qualquer lista que pretendesse ser completa, dificilmente o seria e ainda que o fosse constituiria tanto uma eloqüente manifestação de complexidade quanto de inconclus ão. Mas se por um lado isso implica numa Torre de Babel, representa, por outro, algo muito alvissareiro: a teoria quântica constitui enorme salto cognitivo no sentido da compreensão da realidade física e os termos complexidade e inconclusão podem assumir um amplo espectro de acepções sendo esse mais um elemento de sua fertilidade.

A complexidade ${ }^{2}$, em uma de suas possíveis acepções, pode ser entendida no sentido em que Bachelard reivindica

\footnotetext{
*Versão ampliada da Palestra proferida em Aracajú, Sergipe, Brasil, no dia 2 de agosto de 2002, por ocasião do VII Encontro Sergipano de Física coordenado pelo Professor Osmar de Souza e Silva Júnior do Departamento de Física da Universidade Federal de Sergipe. Numa conversa informal, alguns meses antes da preparação tanto da palestra quanto da composição deste texto, o Professor João Zanetic do Instituto de Física da Universidade de São Paulo nos falou que epistemólogos anglo - saxões por um lado, e latinos (especialmente franceses) por outro, desenvolveram as suas reflexões de maneira mais ou menos independente com pouco ou talvez quase nenhum entrelaçamento e diálogo entre as duas tradições. Pensamos que seja a hora das pessoas que se dedicam a empreender estudos no campo tentarem proceder a uma espécie de aproximação entre essas duas tradições e também entre outras que possivelmente existem, pois isso é enriquecedor. Este trabalho se orienta no sentido de ensaiar uma tal aproximação. Agradecemos a Zanetic por nos ter apontado este fato.

${ }^{1} \mathrm{Na}$ edição brasileira dos Pensamentos de Pascal (Pascal, Coleção 'Os Pensadores', Nova Cultural, São Paulo, 1988, Artigo VI, n. 384, p. 130) podemos ler a tradução do pensamento enumerado como 384 e que escolhemos como epígrafe: "A contradição é um mau sinal de verdade: muitas coisas certas são contraditas; muitas coisas falsas ficam sem contradição. Nem a contradição é sinal de mentira, nem a não contradição é sinal de verdade.”

${ }^{2}$ A fim de melhor esclarecer essa multiplicidade de acepções possíveis para o termo complexidade aqui podemos listar mais duas acepções diferentes daquela desenvolvida no texto central e correspondente à inversão do problema cartesiano da intuição. Uma outra acepção é aquela envolvida em sistemas físicos estudados pela mecânica estatística os quais apresentam 'alta sensibilidade às condições iniciais', ou seja, que uma pequeníssima diferença numa dada casa decimal de uma ou mais grandezas físicas especificando as condições iniciais do sistema, acarreta uma enorme diferença no comportamento ulterior
} 
a inversão do problema da intuição em Descartes: ao invés do ser ilustrar a relação é a relação que passa a iluminar o ser (BACHELARD, 1988: 73-4) ${ }^{3}$; passa-se deste modo para um terreno mais abstrato, mais pantanoso e possivelmente mais vulnerável às artimanhas do 'gênio maligno' 4 . Mas não se deve renunciar aos ideais cartesianos de clareza e distinção que as relações possam porventura nos oferecer (BACHELARD, 1988: 75) ${ }^{5}$. E se essa inversão do problema da intuição cartesiana for capaz de nos fornecer a pista da passagem da epistemologia cartesiana para a epistemologia não-cartesiana, ou epistemologia da complexidade, deveremos dizer que o termo inconclus ão deve se referir à essencial inesgotabilidade do conhecimento, à inexistência de explicações últimas e ao fato de que qualquer que seja a explicação, essa necessariamente remete para outras mais elaboradas e que, ademais, nenhuma explicação é capaz de não deixar resíduos e nem deixar de suscitar problemas tanto ou mais complexos do que aqueles que foram parcialmente resolvidos pelas explicações precedentes. A propósito, ver (POPPER, 2001: 94-173) ${ }^{6}$

E é nesse contexto que temos a intenção de situar os nossos argumentos sobre alguns problemas epistemológicos suscitados pela teoria quântica. Deveremos adiantar que a divergência entre as escolas de pensamento e, mais geralmente, a divergência no seio das comunidades de teóricos de diferentes vocações, é bem maior do que aquilo que se poderia esperar em um primeiro momento. Há surpreendentes e até mesmo desconcertantes posições de partida. $\mathrm{O}$ debate sobre a teoria quântica é referido por inúmeros autores como um verdadeiro pântano conceitual, uma torre de Babel, um diálogo de surdos, exatamente para significar que todos falam, mas são surdos (deliberadamente ou não) diante dos argumentos dos demais. Além disso, há sérias razões para se duvidar se o consenso existente no contexto de correntes majoritárias seja ou não fruto de reflexão genuína, e mesmo de um diálogo minimamente satisfatório entre teoria e experimento, ou mera acomodação motivada por conveniências de várias ordens inclusive pela bem conhecida política de se cortejar grandes chefes a fim de que se venha a evitar uma carreira com sobressaltos, ou seja, àquilo a que Einstein se referiu, numa bela carta a seu amigo Solovine, e em tom de veemente reprovação, ao lamentar o procedimento daquelas pessoas sugestionáveis que sempre estão na moda. (EINSTEIN, 1993: 85)

Podemos também dizer que essa divergência em torno da teoria quântica é, em certa medida, muito estranha e muito peculiar, pois há um enorme abismo entre o extraordinário consenso entre as fórmulas matemáticas da teoria quântica e a profunda dissidência no que diz respeito às interpretações e implicações sobre a realidade física. E, podemos acrescentar, se o pluralismo é bom sinal, o dogmatismo exagerado, notado em amplos círculos de opinião, nada tem de alvissareiro.

A influência e o fascínio exercidos pela teoria quântica atingem não apenas os físicos, matemáticos, químicos e biólogos; eles atingem, além de outros cientistas naturais, também os cientistas sociais, os filósofos, os artistas e mui-

do sistema. Outra acepção, esta muito afeta à própria mecânica quântica, diz respeito à importantíssima propriedade das amplitudes de probabilidade em mecânica quântica as quais são, em geral, complexas, sendo que o termo complexidade neste contexto significa uma quantidade escrita na forma $(\boldsymbol{a}+\boldsymbol{b}$ $\mathbf{i})$, onde $\boldsymbol{a}$ e $\boldsymbol{b}$ são números reais e $\mathbf{i}=(\mathbf{- 1})^{1 / 2}$. Esta propriedade tem implicações profundas no seio da teoria quântica e deste modo podemos dizer que a característica, em geral complexa, das amplitudes de probabilidade em mecânica quântica tem implicações complexas para a física. Veja que nesta última frase usamos o termo 'complexo' em duas acepções distintas: a primeira no sentido estrito da matemática e a segunda como uma espécie de antítese da simplicidade. Evidentemente essas acepções não se excluem mutuamente. Para aprofundar a primeira dessas acepções ver o argumento de Penrose (PENROSE, prefácio a SCHRÖDINGER, 1996) no qual é ressaltado o papel do número complexo no contexto da teoria dos spinores; Penrose também conjectura sobre o papel desses números numa possível solução das questões envolvendo continuidade e descontinuidade, questões essas que foram apontadas por Schrödinger. Podemos noticiar que existem ainda muitas outras acepções para o termo complexidade.

${ }^{3}$ Vejamos, a propósito, os dois excertos de Bachelard que em seguida citaremos, os quais são profundamente elucidativos sobre a questão que estamos levantando para discussão: "Assim, falando de uma epistemologia não-cartesiana, não é sobre a condenação das teses da física cartesiana, ou mesmo sobre a condenação do mecanicismo cujo espírito continuava cartesiano, que pretendemos insistir, mas sim sobre uma condenação da doutrina das naturezas simples e absolutas. Com o novo espírito científico, é todo o problema da intuição que se acha invertido. Pois essa intuição não poderia ser primitiva de hoje em diante; ela é precedida por um estudo discursivo que realiza uma espécie de dualidade fundamental. Todas as noções de base podem de alguma maneira ser desdobradas; podem ser debruadas por noções complementares. Doravante toda intuição procederá de uma escolha; haverá portanto uma espécie de ambigüidade essencial na base da descrição científica e o caráter imediato da evidência cartesiana será perturbado. Descartes não só crê na existência de elementos absolutos no mundo objetivo, mas também pensa que esses elementos absolutos são conhecidos em sua totalidade e diretamente. Em seu nível a evidência é a mais clara. Aí a evidência é completa precisamente porque os elementos simples são indivisíveis. Vemo-los inteiros porque os vemos separados. Assim como a idéia clara e distinta é totalmente isolada da dúvida, assim a natureza do objeto simples é totalmente separada das relações com os outros objetos. Nada mais anticartesiano do que a lenta modificação espiritual que impõe as aproximações sucessivas da experiência, sobretudo quando as aproximações mais acentuadas revelam riquezas orgânicas desconhecidas pela informação primeira. É o caso, repitamo-lo, da concepção einsteiniana cuja riqueza e valor complexo fazem aparecer de repente a pobreza da concepção newtoniana.É o caso também da mecânica ondulatória de Louis de Broglie que completa em toda a força do termo a mecânica clássica e a própria mecânica relativista.'(BACHELARD, 1988: 73) [As ênfases em caracteres simplesmente itálicos foram acrescentadas por nós; a ênfase em caracteres em negrito é de Bachelard]. Vejamos o segundo excerto de Bachelard: “ Confronte-se mais uma vez com esta epistemologia cartesiana o ideal de complexidade da ciência contemporânea; lembrem-se as múltiplas reações do novo pensamento científico contra o pensamento assintáxico! A ciência contemporânea se baseia numa síntese primeira; realiza em sua base o complexo geometria-mecânicaeletricidade; expõe-se no espaço-tempo; multiplica seus corpos de postulados; coloca a clareza na combinação epistemológica, não na meditação separada dos objetos combinados. Em outras palavras, substitui a clareza em si por uma espécie de clareza operatória. Longe de ser o ser que ilustra a relação, é a relação que ilumina o ser (BACHELARD, 1988: 74) (As ênfases em caracteres itálicos das últimas duas linhas desta última citação foram acrescentadas por nós).

${ }^{4}$ Aqui neste contexto, a expressão 'gênio maligno' é uma figura de linguagem. Trata-se daquela inteligência 'sobre-humana' a nos mostrar erros e contraexemplos onde para nós tudo era domínio de sólidas certezas. Quais são os princípios sólidos e inabaláveis que constituem certezas que nos imunizam de quaisquer que sejam as diabruras do 'gênio maligno'? A História da Ciência (inclusive da Matemática) levou as pessoas a não mais acreditarem de maneira tão essencialista quanto se pensava fosse possível no século XVII.

${ }^{5}$ Vejamos mais este importante excerto de Bachelard: "Assim, se se trata de ensinar a ordem nas notas, a clareza na exposição, a distinção nos conceitos, a segurança nos inventários, nenhuma lição é mais frutuosa do que a lição cartesiana.”(BACHELARD, 1988: 75).

${ }^{6}$ Trata-se do capítulo 2 (texto em italiano e em alemão) de 'La Riduzione Scientifica e L'essenziale incompletezza della Scienza' e de 'Wissenschaftliche Reduktion und die Essentielle Unvollständigkeit der Wissenschaft.' 
tas outras categorias profissionais; eles atingem, de fato, até mesmo simples curiosos. Sem esquecer nem desmerecer que a curiosidade constitui dimensão importantíssima de entusiasmo frente aos problemas cognitivos, e que para pensar não é necessário se ater a qualquer que seja a categoria profissional, embora a inserção na estrutura formal de ensino e pesquisa seja recomendável, é perfeitamente compreensível que idéias como salto quântico, consciência do sujeito, dissolução da realidade, relações não-causais, indeterminismo, não-localidade, entre outras, constituam um grande atrativo no imaginário das pessoas, quase sempre acompanhado de grande precipitação e ligeireza de reflexão.

Quando a teoria quântica é veiculada no processo de educação científica e de ensino então as coisas se apresentam de uma maneira ainda mais preocupante e crítica. Frequientemente, quando a teoria quântica é apresentada nos cursos regulares, desaparecem todas as complexas polêmicas da história real e passam a aparecer reconstruções racionais tão forçadas e dirigidas que o objetivo precípuo é o de fomentar a crença de que o pluralismo somente seria válido para o processo de discussão do turbilhão da dúvida ${ }^{7}$ mas que uma vez atingida a sintese final apenas existiria uma e somente uma maneira justa e correta de se conceber a multiplicidade dos fenômenos. Mas será que as coisas são de fato assim? Não seria no diálogo eternamente fértil entre diferentes concepções, diálogo esse complementado por um outro diálogo igualmente fértil entre teoria e experimento, que uma concepção organizadora, e que não exclui definitivamente suas rivais, nutre a sua fertilidade? Ademais, poderíamos perguntar se haveria a possibilidade de uma organização do pensamento que não deixasse resíduos nem pontas e que fosse tão definitivamente definitiva que não permitisse suscitar outros tantos problemas pelo menos igualmente complexos e até mesmo plenos de dúvidas? Não seria a história da ciência a demonstrar que programas científicos de pesquisa dantes dados como "sepultados" costumam "ressuscitar" e fertilizar o pensamento?

No entanto, a opção adotada pela maioria esmagadora dos cursos tem sido a de apresentar a mecânica quântica de uma maneira mais ou menos prescriptiva e fortemente instrumental possivelmente com o fito de atender às demandas da ciência 'normal' descrita por Kuhn (KUHN, 1975; 1996) ou seja, com o objetivo de facilitar as coisas para propiciar aos jovens um engajamento na pesquisa sem "perdas de tempo" e esforços "inúteis". Não seriam divisões sócioeconômico-políticas do trabalho como esta muito mais responsáveis pela fragmentação - não somente do conhecimento mas também da própria vida social- do que o tão caluniado método cartesiano que tão bons serviços prestou à geometria e à física ? E não seria o caso de se pensar numa causalidade complexa no sentido de Morin (MORIN, 2001): reformar o pensamento para que venhamos a reformar as instituições de maneira concomitante com a reforma das instituições para que venhamos a reformar o pensamento?
E quando falamos de fragmentação não estamos falando da especialização séria que busca reduzir para aprofundar, especialização essa que imbuída de entusiasmo cognitivo se encaminha na direção da complexidade dos fenômenos: esta é uma ciência desejável e genuína e, deste modo, a sua prática deve ser incentivada (VINTI, 1999: 155) ${ }^{8}$. Consideramos sim, (BASTOS FILHO, 2000, e 2001) que deve ser séria e criticamente repensada a fragmentação ligada aos exageros da ciência chamada de 'normal', fruto de uma exagerada divisão social do trabalho, que incentiva o carreirismo e cujos praticantes receberam de Popper o epíteto de cientistas mal ensinados (POPPER, 1979: 63-71). É também muito importante deixar claro que aqui não condenamos a organização do pensamento consubstanciada pelos livros textos que têm importante papel didático e para os quais as disciplinas teóricas e experimentais encontram necessária sistematização. O que não podemos concordar é com a obrigatoriedade de se seguir capítulo por capítulo os paradigmas em voga e cegamente fazer uma opção única e exclusiva por uma dada sistematização, por mais méritos que essa venha a ter e qualquer que seja ela. Mais uma vez, evocamos o pluralismo e a abordagem temperante que pondera e critica, mas que também sabe apreciar e incorporar o que julga proveitoso e edificante.

Aqui faremos uma escolha de temas e somente abordaremos alguns poucos dos complexos problemas suscitados pela teoria quântica incentivando uma discussão sobre os mesmos.

Em primeira instância, teceremos algumas considerações sobre os problemas da Realidade, da Compreensibilidade e da Causalidade. Em segunda instância, e assumindo uma posição de crítica, falaremos sobre o Positivismo e sua influência na teoria quântica e na concepção de mundo que foi gerada a partir de sua considerável influência em outros campos de atividade. Em uma terceira instância procederemos a uma articulação que visa uma aproximação entre a epistemologia da complexidade de Bachelard, a filosofia do racionalismo crítico de Popper e a metodologia lakatosiana dos programas científicos de pesquisa. Para essa articulação torna-se imprescindível trazer à baila a discussão do conceito de 'experimentos cruciais'. Procuraremos tirar algumas implicações de tudo isso para a Educação e para o Desenvolvimento Cultural das pessoas e dos formadores de opinião.

\section{Realidade}

Um dos teóricos avançados da teoria quântica e da teoria da relatividade, Franco Selleri, (SELLERI, 1986; SELLERI, 1990) tem insistido sobre a surpreendente e extraordinária falta de consenso entre os pais fundadores da teoria quântica acerca de problemas que à primeira vista deveriam conhecer

\footnotetext{
${ }^{7}$ Inspiramo-nos aqui no belo título do livro coletivo organizado por Lino Conti e Marco Mamone Capria, La scienza e $i$ vortici del dubbio, Edizioni Scientifiche Italiane, Nápoles, Itália, 1999.

${ }^{8}$ Vinti escrevendo sobre a importância da especialização na obra de Bachelard argumenta: "Così Bachelard, respingendo 'le abituali omelie contro la specializzazione', fa di essa uno dei caratteri precipui dell'operare scientifico anche a livello teórico; la specializzazione è il segno più chiaro dell'impegno metodologico dell'operare scientifico; lungi dall'essere espressione di un' applicazione limitata, circoscritta, essa è ciò che permette l'effettiva 'realizzazione di una cultura generale', ciò che mostra 'la reale fecondità della cultura', 'la reale vivacità della cultura'.” A tradução deste texto em italiano para o português é o seguinte: “Assim, Bachelard ao recusar 'a habitual cantilena contra a especialização' faz desta uma das características precípuas do fazer ciência até mesmo em nível teórico; a especialização é o sinal mais claro do empenho metodológico do fazer ciência; longe de ser expressão de uma aplicação limitada, voltada para si própria, é o que permite a efetiva 'realização de uma cultura geral', o que mostra 'a real fecundidade da cultura', a 'real vivacidade da cultura'.
} 
um mínimo de acordo. Essas questões dizem respeito à realidade, à compreensibilidade e à causalidade. Popper, em um belo e breve prefácio a um dos livros de Selleri, aborda com sutileza e talvez, com maior destaque, o problema da compreensibilidade. No entanto, é de bom alvitre que esses problemas, que estão fortemente relacionados entre si, sejam vistos em conjunto.

De que trataria, pois, o problema da realidade? Que estatuto ontológico teriam esses objetos de que fala a mecânica quântica? Em outras palavras, em que constituiriam entidades como elétrons, prótons, fótons, mésons, pións, etc? Seriam entidades ontologicamente existentes, ou entidades mneumônicas, meros construtos teóricos para 'salvar os fenômenos' ou ainda, meras hipóteses de trabalho?

Tudo isso é surpreendente pois se levarmos a sério a famosa frase de Wheeler segundo a qual "no phenomenon is a phenomenon until it is an observed phenomenon" 9 qualquer realidade que não tenha sido ainda observada deveria ser negada enquanto tal pois ela não pertenceria ao mundo dos fenômenos. Limitando de tal maneira o conceito de realidade e a reduzindo apenas ao universo dos fenômenos observados, então não se poderia atribuir realidade à lua nos instantes em que para ela não dirigirmos os nossos olhares. (PAIS, 1995: 3) ${ }^{10}$

Que realidade se poderia conceber num mundo no qual ela própria não teria autonomia e fosse exclusivamente criada por atos de medida? Que significado teria essa dissolução da realidade? Por que confundir a realidade intensa dos quanta e suas aniquilações e criações com um mundo evanescente e virtual?

E que paradoxo desconcertante, conceber os objetos macroscópicos como ontologicamente objetivos e independentes de nossas medidas e desejos, e ao mesmo tempo conceber os seus constituintes microscópicos como evanescentes criaturas produzidas por atos de medida e coisas do gênero? (BASTOS FILHO, 1999a, 2002a).

Mas Einstein protestou de maneira veemente contra essa moda de dissolução da realidade comparando os seguidores dessa idéia a cavalos. Einstein, numa carta escrita em alemão no dia 10 de abril de 1938 e endereçada a seu amigo Solovine, assim se expressou, segundo a seguinte tradução em inglês:

"In Mach's time a dogmatic materialistic point of view exerted a harmful influence over everything; in the same way today, the subjective and positivistic point of view exerts too strong an influence. The necessity of conceiving of nature as an objective reality is said to be superannuated prejudice while the quanta theoreticians are vaunted. Men are even more susceptible to suggestion than horses, and each period is dominated by a mood, with the result that most men fail to see the tyrant who rules over them". (EINSTEIN, 1993: 85) ${ }^{11}$

Einstein se insurgiu com ênfase contra a atitude de persuadir e ou de intimidar aqueles que defendem a tese segundo a qual existe uma realidade objetiva independente de nós próprios, ainda que venhamos a conceber que nós também somos capazes de mudar a realidade, da qual somos parte, se viermos a intervir sobre ela. Einstein não era um realista ingênuo; ele era absolutamente cônscio da complexidade das relações sujeito/objeto, mas também sabia, por reflexão duradoura e profunda, que a enorme complexidade dessas relações não seria capaz de demitir a realidade objetiva como irrelevante ou de simplesmente proceder a sua dissolução. Einstein considerou uma disparatada lavagem cerebral a moda de se considerar como um preconceito obsoleto e superado a adoção que tem como ponto de partida a postulação da existência de uma realidade objetiva. E como é muito comum o medo de ser considerado como fora de moda e, conseqüentemente, o medo de ser ridicularizado por se conceber algo assim tão "antigo" e "ultrapassado", então o que se viu foi uma adesão em massa à nova moda. A coisa é muito mais deprimente do que parece à primeira vista, pois a nova moda não é acatada por reflexão, nem mesmo pelo conjunto de resultados que constituiriam um inventário de dados experimentais, mesmo porque nenhum inventário do gênero poderia justificar qualquer que fosse a adoção filosófica acerca duma eventual dissolução ou não da realidade. A adoção filosófica realista é um ponto de partida e não se pode provar sequer a existência da realidade. O deprimente é que se trata da força de persuasão dos grandes chefes, da submissão, do medo, da falta de autonomia intelectual, da falta de pensamento, da falta daquilo que, como Pascal argumentou, é justamente onde reside a dignidade humana. (PASCAL, 1948: 162-3 ; PASCAL, 1988: $123-4)^{12}$

\footnotetext{
${ }^{9}$ A frase de Wheeler pode ser traduzida assim: "Nenhum fenômeno é um fenômeno até quando seja um fenômeno observado".

${ }^{10}$ Pais escreve o seguinte: "Deve ter sido por volta de 1950. Eu acompanhava Einstein no percurso do Instituto de Estudos Avançados para sua casa, quando ele parou de repente, voltou-se para mim e me perguntou se eu realmente acreditava que a Lua só existia quando eu olhava para ela."

${ }^{11}$ Podemos traduzir a citação de Einstein para o português assim: "Na época de Mach, um ponto de vista materialista dogmático exerceu uma influência nociva sobre tudo; da mesma maneira, o ponto de vista subjetivo e positivista exerce uma grande influência hoje. A necessidade de conceber a natureza como uma realidade objetiva é tida como um preconceito obsoleto enquanto os teóricos dos quanta são glorificados. Os homens são mais susceptíveis de serem influenciados do que os cavalos e cada período é dominado por uma moda com o resultado de que muitos homens nem sequer percebem o tirano que lhes domina."

${ }^{12}$ Podemos enxergar em cheio os argumentos de Pascal ao ler os seus pensamentos enumerados respectivamente por 346 , 347 e 348 ; no texto original em francês são eles: 346. “Pensée fait la grandeur de l'homme.” ; 347. "L'homme n'est qu'un roseau, le plus faible de la nature; mais c'est un roseau pensent. Il ne faut pas que l'univers entier s'arme pour l'écraser: une vapeur, une goutte d'eau, suffit pour le tuer. Mais, quand l'univers l'écraserait, l'homme serait encore plus noble que ce qui le tue, parce qu'il sait qu'il meurt, et l'avantage que l'univers a sur lui; l'univers n'en sait rien. Toute notre dignité consiste donc en la pensée. C'est de là qu'il faut nous relever et non d'espace et de la durée, que nous ne saurions remplis. Travaillons donc à bien penser: voilà le principe de la morale."; 348. "Roseau pensent-Ce n'est point de l'espace que je dois chercher ma dignité, mais c'est du règlement de ma pensée. Je n'aurai pas davantage en possédant des terres: par l'espace, l'univers me comprend et m'engloutit comme un point; par la pensée, je le comprends.”. Agora vejamos a tradução desses mesmos pensamentos para o português: 346. "O pensamento faz a grandeza do homem." ; 347. "O homem não passa de um caniço, o mais fraco da natureza, mas é um caniço pensante. Não é preciso que o universo inteiro se arme para esmagá-lo: um vapor, uma gota de água, bastam para matá-lo. Mas mesmo que o universo o esmagasse, o homem seria ainda mais nobre do que quem o mata, porque sabe que morre e a vantagem que o universo tem sobre ele; o universo desconhece tudo isso. Toda a nossa dignidade consiste, pois, no pensamento. Daí é que é preciso nos elevarmos, e não do espaço e da duração, que não poderíamos preencher. Trabalhemos, pois, para bem pensar; eis o princípio da moral." ; 348 . “-Caniço pensante- Não é no espaço que
} 
E que tipos de argumentos foram lançados para defender uma tese tão pouco plausível como a dissolução da realidade mesmo levando-se em conta que não se pode provar nem a sua existência nem sequer a sua eventual inexistência?

Evidentemente foram argumentos de diferentes teores. Em relação a Einstein, não faltaram aqueles que, por um lado lhe prestavam louvores do tipo glorificante que o enalteciam como o maior cientista do século $X X$ e outros epítetos do gênero, mas por outro tentavam desqualificá-lo atribuindo-lhe um caráter "conservador" que segundo tais acusadores seria próprio de alguém apegado a um realismo "antiquado" que a nova física a cada dia contradizia.

Mas será que um parecer do gênero faz justiça a alguém cujo espírito criador tenha a sua estatura e tendo em vista ainda que ele continuamente fazia revisões críticas de sua própria obra, mas que também tinha as suas convicções fortes?

A resposta a esta última questão envolve uma certa complexidade, pois trataria de estudo detalhado acerca de uma série de singularidades da obra einsteiniana inclusive da história de sua aceitação ${ }^{13}$. No entanto, é possível dar uma resposta, ainda que parcial, se optarmos por um atalho.

Sem dúvida, um estudante atento de física moderna pode perfeitamente concluir alguma coisa, mediante suas próprias reflexões, emitindo conseqüentemente um parecer acerca da trajetória intelectual de Einstein, ou seja, se ela pecaria ou não por conservadorismo.

Vejamos a explicação einsteiniana do efeito fotoelétrico, fenômeno esse que, como se sabe, não era inteligível no quadro teórico do eletromagnetismo de Maxwell. Einstein supôs uma entidade que concentrasse energia em uma pequeníssima região do espaço, entidade essa que era totalmente destruída enquanto tal, ao fornecer toda a sua energia para fazer com que - em primeira instância - uma parte dessa energia fosse utilizada para que um elétron do metal constituinte do catodo vencesse a barreira de potencial típica desse metal e dele pudesse emergir, e - em segunda instância - outra parte da energia proveniente daquela entidade totalmente destruída fosse responsável pela energia cinética adquirida pelo elétron emergente a fim de ele pudesse passar do catodo para o anodo da célula fotoelétrica e, conseqüentemente, fechar a corrente.

No contexto do efeito fotoelétrico aquela entidade que Einstein imaginou existir era totalmente destruída; ela, algum tempo depois, seria chamada de fóton. Ela era totalmente destruída, mas não a sua energia que, como vimos, era inteiramente utilizada para fazer com que um elétron vencesse a barreira de potencial do metal constituinte do catodo e ainda emergisse do catodo com uma dada energia cinética a fim de fechar a corrente fotoelétrica.

Tratava-se de uma explicação revolucionária e extraordinariamente inovadora em vários sentidos dos termos revolução e inovação. Tivemos ocasião de tecer considerações sobre o assunto (BASTOS FILHO, 1999a: 421-7; 2002a: 374-9) e por isso vamos aqui reiterar comentários semelhantes, mas de maneira mais breve. Vejamos alguns desses sentidos para que venhamos a ter uma idéia precisa de como uma idéia extremamente simples de um ponto de vista meramente matemático pôde e ainda pode ser enormemente fértil dos pontos de vista físico e epistemológico.

Einstein oferecia uma explicação simples de um fenômeno não passível de entendimento dentro do quadro conceitual do eletromagnetismo de Maxwell. No contexto do eletromagnetismo de Maxwell, a energia eletromagnética total era o resultado duma integração sobre o volume nas regiões em que os campos, elétrico e magnético, fossem não nulos. A energia dependia do quadrado das amplitudes dos campos e as freqüências não desempenhavam qualquer papel relevante, pois independentemente de quais fossem as freqüências envolvidas das ondas eletromagnéticas se os quadrados das amplitudes dos campos, elétrico e magnético, fossem os mesmos, então a energia eletromagnética total seria a mesma. No entanto, uma grande energia total de uma

devo buscar minha dignidade, mas na ordenação de meu pensamento. Não terei mais, possuindo terras; pelo espaço, o universo me abarca e traga como um ponto; pelo pensamento, eu o abarco."

${ }^{13}$ A aparentemente paradoxal combinação entre, por um lado, a alta reverência que se nutria pela extraordinária excelência do pensamento de Einstein e, por outro, as manifestações de marginalização político-científica sofridas por Einstein são elementos que podem ser perfeitamente compreendidos ao se analisar as coisas de uma maneira abrangente. Einstein houvera dito em carta que "Aqui em Princeton consideram-me um velho maluco" ["Ici à Princeton, on me considère comme um vieux fou"] (BORN, 1969: 161 apud SELLERI, 1986: 26). David Lindley, um antigo Associate Editor da revista Nature e que depois foi Senior Editor da revista Science tecendo considerações sobre Einstein assim se expressou: "Because his interests diverged so far from the mainstream of physics, Einstein established no real lineage. He is revered, but unlike Niels Bohr and Wolfgang Pauli and Werner Heisenberg and the other founders of twentieth-century physics, he was never a father figure to researchers of a new generation." (LINDLEY, 1993: 3-4). Em português o texto de Lindley pode assim ser traduzido: "Em virtude de seus interesses terem divergido largamente da corrente principal da física, Einstein não gerou uma linha de seguidores intelectuais. Ele é reverenciado, mas diferentemente de Niels Bohr, Wolfgang Pauli e Werner Heisenberg ele nunca foi uma figura de orientador para pesquisadores de uma nova geração." Este, de fato, é um aspecto importante. No entanto, aquela caracterização que o estigmatizava como um "ilustre desconhecido" funcionário do escritório de patentes de Berna (Suíça) que em 1905 procurava 'desesperadamente reconhecimento' tem muito de folclore; antes de seus famosos trabalhos de 1905, Einstein já havia publicado entre 1901 e 1904, bem uns 5 trabalhos na Annalen der Physisk perfazendo um total de mais do que 70 páginas (MAMONE CAPRIA, 1999a: 298; 2002a: 262). Logo, pode-se dizer, tendo em vista o enorme prestígio da revista na época e as dimensões das comunidades científicas praticante de física na Alemanha e em geral na Europa, que, já nessa época, Einstein não era um 'ilustre desconhecido'. Outrossim, embora Einstein já naquela época tivesse bastante autonomia de pensamento, ele soube cativar o apreço dos grandes chefes e líderes da pesquisa na Alemanha por meio de citações, as quais, não obstante, eram bastante pertinentes (MAMONE CAPRIA, 1999a: 314-322; 2002a: 276-284). $\mathrm{O}$ fato dessas citações serem bastantes pertinentes e, ademais, de estarem conectadas com a alta qualidade de seu trabalho, não significa que Einstein não tivesse uma estratégia política de se aproximar dos influentes cientistas da física na Alemanha de então. Não apenas Planck, mas muitos outros influentes pesquisadores de então ajudaram de maneira relevante, e talvez até mesmo decisiva, na repercussão de seu trabalho. Numa carta de Einstein a Solovine escrita em Berna (Suíça) no dia 3 de maio de 1906, Einstein assim se expressou sobre a repercussão de seus trabalhos e o especial - e acrescentaríamos até um talvez decisivo - apoio de Max Planck ao seu trabalho: "Meine Arbeiten finden viel Würdingung und geben Anlass zu weiteren Untersuchungen. Prof. Planck (Berlin) schrieb mir neulich darüber." (EINSTEIN, 1993: 20) . Este trecho da carta de Einstein a Solovine foi traduzida assim para o inglês: “ My works are highly esteemed and are giving rise to further research. Professor Planck (Berlin) has written to me recently concerning this.” (EINSTEIN, 1993 : 19). Em português, traduziríamos assim: "Os meus trabalhos estão sendo muito apreciados e estão proporcionando pesquisas ulteriores. Professor Planck (Berlim) escreveu-me recentemente tocando nisso." 
luz de baixa freqüência (grande comprimento de onda) não era capaz de produzir o efeito enquanto uma pequena energia total de uma luz de relativamente alta freqüência (relativamente baixo comprimento de onda) era já o bastante para que o efeito fotoelétrico fosse produzido. Logo, o eletromagnetismo de Maxwell era claramente inadequado, enquanto referencial teórico, para dar conta do fenômeno.

Tendo em vista a insuficiência teórica do eletromagnetismo de Maxwell para dar conta desse fenômeno, Einstein, lançando mão de uma conjectura audaciosa que se revelou fertilíssima, propôs a existência concreta de uma entidade introduzida por ele pela primeira vez - cuja a energia correspondente se encontrava localizada e cujo valor era $E=h \nu$ sendo $h$ a constante de Planck, aquela mesma que aparecia no contexto de um problema muito diferente que era o problema estatístico da radiação eletromagnética em equilíbrio com a matéria a uma temperatura $T$ (o problema do corpo negro). Aqui, o problema não era estatístico e podia ser estudado por meio da simplicíssima fórmula,

$$
h \nu=\Phi+E_{C i n}
$$

em que se pode ver que a energia do fóton que desaparece é igual à soma das energias, respectivamente, para vencer a barreira de potencial, energia essa denotada por $\Phi$, e, além dessa, para fornecer uma certa energia cinética $E_{C i n}$ ao elétron emergente.

Einstein conciliou os resultados eletromagnéticos de uma distribuição espacial macroscópica da energia nas regiões de campos, elétrico e magnético não nulos, com uma distribuição localizada microscópica carregada pelo fóton, distribuição localizada essa necessária para tornar inteligível o efeito fotoelétrico, fenômeno que o eletromagnetismo de Maxwell não era capaz de explicar. Introduzia ele com este notável feito, uma nova propriedade da luz além daquelas conhecidas pelo eletromagnetismo. Introduzia ele também, a primeira formulação da dualidade da luz. A fórmula $E=h \nu$ representava uma entidade cuja energia era localizada numa pequeníssima região do espaço e que, não obstante, era associada a uma onda (que é uma entidade extensa) cuja freqüência $\nu$ era a da luz monocromática correspondente cujo valor se situasse em um domínio para o qual fosse possível o efeito fotoelétrico. De Broglie introduziu, tempos depois, uma outra relação dualista, a famosa relação $p=h / \lambda$, onde $p$ denota a quantidade de movimento do corpúsculo, $h$ a constante de Planck e $\lambda$ o comprimento de onda da onda associada. Ambas as relações, tanto a de Planck-Einstein como a de De Broglie são patrimônios cognitivos, pilares da teoria quântica em quaisquer que sejam as interpretações dadas à mecânica quântica por mais estranhas e esotéricas que sejam.

Vejamos um aspecto interessante e raramente notado. Em 1905, não se conhecia qualquer entidade, como o fóton, descrita através de uma equação energética simplicíssima como a que acima foi escrita e que desaparecesse inteiramente, enquanto tal, mas que a sua energia fosse rigorosamente conservada. Analisando, no entanto, quase um século após, isso não parece tão revolucionário. Hoje na física de altas energias assiste-se aos fenômenos de aniquilação e criação de partículas. Por exemplo, uma partícula como o elétron conjuntamente com a sua anti-partícula (o pósitron) podem aniquilar-se e, resultantes dessa aniquilação emergem dois fótons de raios gama; e vice-versa dois fótons de raio gama podem também dar vazão à criação de um par partícula/anti-partícula como é o caso da criação do elétron e de sua anti-partícula, o pósitron. Fenômenos como esses existem aos montes em física de altas energias e Einstein com a extraordinária conjectura de uma entidade que desaparecesse inteiramente enquanto tal aliada à sua simples e bela explicação do efeito fotoelétrico foi um dos vaticinadores dessa extraordinária descoberta do século XX. A idéia de Einstein ainda estava inteiramente de acordo com a sua teoria da relatividade, pois o par partícula/anti-partícula tinha massa de repouso e energia de repouso. Os fótons não têm massa de repouso, mas têm energia e massa associadas às suas respectivas energias de movimento por meio da fórmula $E=m c^{2}$. O pensamento de Einstein tinha uma linha de coerência com o seu programa cient ífico de pesquisa que era realista e racionalista. Nunca é demasiado lembrar que naquele mesmo ano de 1905 ele, além do trabalho sobre o efeito fotoelétrico e os dois trabalhos sobre relatividade, ainda estava envolvido com pesquisas no campo da mecânica estatística e com um célebre trabalho sobre o movimento browniano, este último considerado como um importante passo, talvez mesmo definitivo, da afirmação do paradigma atomista na física em oposição às idéias positivistas de recusa do atomismo como aquelas de Ernest Mach.

Não é irônico que alguém com a audácia e a criatividade intelectuais para introduzir as extraordinárias idéias de fóton, de massa associada à energia de movimento, de ter afirmado o paradigma atomista tão brilhantemente e de ter sido um preconizador, senão um precursor, das aniquilações e criações em altas energias, fosse tão enfático e veemente contra os exageros e desatinos daqueles que queriam evaporar a realidade?

Não seria isso um sinal de compromisso verdadeiro com o realismo e a racionalidade, tão seriamente bombardeados pelos dramáticos e trágicos acontecimentos do sangrento século XX, tão pleno de ideologias que atentaram contra a racionalidade e a dignidade humana?

E essas idéias ainda não estavam de todo propagadas, pois, mais recentemente, alguns autores, talvez quem sabe, os sucedâneos - pelo menos em inspiração - daqueles que queriam dissolver a realidade, agora reivindicam pelas evaporações e dissoluções da história, do progresso, preconizam o fim da ciência e o fim do próprio homem.

Mas será que a teoria quântica e suas fórmulas matemáticas permitiriam extensões tão hiperbólicas como essas?

Antes do encerramento desta seção é importante que venhamos a analisar algumas reações que foram desencadeadas contra a idéia de Einstein do quantum de energia carregado pelo fóton. E aí Einstein teve que enfrentar tanto a crítica de positivistas quanto a crítica de cientistas/filósofos realistas como Planck.

Em 1913, no arrazoado por ocasião da proposta para que Einstein fosse membro da seleta Academia Prussiana de Ciências, Planck, Nernst, Rubens e Warburg, depois de rasgados elogios a Einstein concluíram com uma explícita desaprovação acompanhada de um indulgente perdão; escreveram eles:

"Em suma, pode-se dizer que dificilmente haverá um entre os grandes problemas em que a física moderna é tão rica para o qual Einstein não tenha dado uma contribuição notável. 
O fato de, por vezes, ter errado o alvo em suas especulações, como, por exemplo, na sua hipótese dos quanta de luz, não pode ser esgrimido demais contra ele, pois não é possível introduzir idéias realmente novas, mesmo nas ciências mais exatas, sem algumas vezes correr riscos". (PLANCK et. al. apud PAIS, 1995: 453).

Também em 1912, Sommerfeld assim se expressou:

"Einstein extraiu as maiores conseqüências da descoberta de Planck [do quantum de ação] e transferiu as propriedades quânticas dos fenômenos de emissão e absorção para a estrutura da energia da luz no espaço, mas creio que não mantém hoje o seu ponto de vista inicial [de 1905] em toda a sua audácia”. (SOMMERFELD apud PAIS, 1995: 454)

E mesmo Millikan que tão brilhantemente havia confirmado experimentalmente a fórmula de Einstein do efeito fotoelétrico escreveu em 1916:

"Apesar do êxito[...] aparentemente completo da equação de Einstein [para o efeito fotoelétrico], a teoria física de que estava destinada a ser a sua expressão simbólica mostrou-se tão insustentável que o próprio Einstein, creio, não a defende mais". (MILLIKAN apud PAIS, 1995 : 454)

Ao examinar a reação aos quanta de luz de Einstein, o físico teórico Abraham Pais, um conhecedor da obra einsteiniana, chegou à conclusão de que essa reação era tão grande que a prudência de Einstein (poderíamos acrescentar, uma virtude que convém aos sábios) foi freqüentemente confundida com hesitação. Faz-se mister ressaltar que prudência $\mathrm{e}$ hesitação são coisas bem distintas. Além disso, podemos constatar que em ambos os relatos imediatamente acima, tanto no de Sommerfeld quanto no de Millikan, esses autores declaram crer que Einstein não sustenta mais o mesmo ponto de vista que houvera sustentado em 1905.

Mas, em que pese muitos "crerem" certas e determinadas coisas, talvez mesmo insuflados pela atmosfera de forte reação contra as idéias do quantum de Einstein, o especialista Pais faz o seguinte comentário:

"Todavia, julgando pelos seus trabalhos e cartas, não encontro qualquer evidência de que em algum momento tivesse rejeitado algumas das suas afirmações de 1905". (PAIS, 1995: 454)

Este parecer de Pais é muito importante pois revela que Einstein tinha fortes convicções no caráter plausível e justo de suas idéias, e em especial, naquilo que dissesse respeito ao quantum de luz. Logo, havia muito mais de convicção do que de eventuais hesitações. E quando Einstein declara o caráter provisório do quantum de luz é muito mais por uma questão de prudência e de certeza epistemológica quanto à essencial incompleteza de qualquer que seja a explicação, ou seja, no caráter essencialmente incompleto do conhecimento, ou ainda, no aspecto essencialmente recorrente das grandes idéias. Isso, podemos dizer, é coisa muito diferente de qualquer que seja a hesitação ou medo dos pareceres dos grandes e influentes chefes que, sem dúvida, nutriam por ele um misto de grande admiração, acompanhada de cooperação e competição. E para consubstanciar os argumentos em prol da prudência de Einstein - talvez mesmo de sua modéstia socrática, mas não de hesitação pusilânime - escolhemos duas passagens que se encontram referidas no livro de Pais (1995).

No Congresso Solvay de 1911, Einstein assim se expressou:

"Insisto no caráter provisório deste conceito [quanta de luz], que não parece reconciliável com as conseqüências, verificadas experimentalmente, da teoria ondulatória”. (EINSTEIN, apud PAIS, 1995: 454)

E já nos anos finais de sua vida, em 1951, numa carta ao seu dileto amigo, o italiano Michele Besso, escrevia ele:

"Die ganzen 50 Jahre bewusster Grübelei haben mich der Antwort der Frage "Was sind Lichtquanten' nicht näher gebracht”. (EINSTEIN apud PAIS, 1995: 453) ${ }^{14}$.

É ainda possível se inferir sobre a prudência, mas não hesitação de Einstein em um excerto muito caro a nós brasileiros, pois foi tirado de uma das duas conferências proferidas por Einstein no Rio de Janeiro ${ }^{15}$ em maio de 1925 . Nela Einstein dizia:

"Até pouco tempo acreditava-se que com a teoria ondulatória da luz, na sua forma eletromagnética, se tivesse adquirido um conhecimento definitivo da natureza da radiação. Sabese entretanto, há cerca de 25 anos, que aquele trabalho, embora representando com justeza as propriedades eletromagnéticas da luz, não permite explicar as propriedades térmicas e energéticas da radiação. Uma nova concepção teórica, a teoria dos quanta, semelhante à teoria de Newton, apareceu ao lado da teoria ondulatória da luz e adquiriu, pelo seu poder de explicação uma posição segura na ciência. Uma síntese da teoria dos quanta e da ondulatória não se conseguiu, até hoje, apesar de todos os

\footnotetext{
${ }^{14} \mathrm{~A}$ tradução para o português é a seguinte: “Todos estes cinqüenta anos de meditação não me têm aproximado da resposta à questão: que são os quanta de luz ?"

${ }^{15}$ Einstein esteve na Argentina (Buenos Aires) no período de 25 de março a 23 de abril de 1925. Durante a sua viagem de ida para a Argentina o navio que o conduzia atracou no porto do Rio de Janeiro no dia 21 de março de 1925 . Einstein visitou muito brevemente a nossa então capital da República tendo no dia seguinte prosseguido a sua viagem. Na volta da Argentina, Einstein permaneceu de 4 de maio a 12 de maio no Rio de Janeiro e depois prosseguiu na sua viagem para a Europa. Durante esses dias de sua segunda estada no Brasil Einstein cumpriu intensa programação cultural: visitou instituições como o Instituto Maguinhos (Fundação Oswaldo Cruz), o Hospital Juliano Moreira, o Observatório Nacional e o Jardim Botânico; ele também deu entrevistas e proferiu duas concorridas palestras.
} 
esforços dos cientistas. Há pouco tempo, tentou Bohr, juntamente com Kramers e Slater explicar teoricamente, as propriedades da luz, sem lançar mão da hipótese de que toda a radiação é constituída de quanta". (EINSTEIN apud RICIERI, 1988: 55)

Como podemos ver, mesmo numa época em que a física brasileira estava na sua pré-história ${ }^{16}$, e que portanto a sua comunidade científica era muito diferente daquela de hoje, Einstein não sentiu necessidade de fazer proselitismo de seus quanta tendo citado respeitosamente uma tentativa de alternativa rival como a de Bohr, Kramers e Slater que, justamente, não considerava a sua idéia.

Max Planck que tanto houvera apoiado os trabalhos de Einstein de 1905 (sobre a relatividade, e sobre o movimento browniano) e com o seu apoio tivesse dado, mediante o seu grande prestígio, enorme alento à penetração das idéias de Einstein nos seios das comunidades científicas, alemã e mundial, houvera já em 1907 feito ao próprio Einstein objeções à sua idéia de quantum de luz. Planck escrevia para Einstein no dia 6 de julho de 1907:

"Não procuro o significado do quantum de ação [quanta de luz] no vazio, mas sim em lugares onde a absorção e a emissão ocorrem, e assumo que o que acontece no vazio é rigorosamente descrito pelas equações de Maxwell". (PLANCK apud PAIS, 1995: 455)

Abraham Pais (PAIS, 1995: 456) analisou as três primeiras contribuições seminais dadas à teoria quântica, a saber, a de Planck (1900) sobre o corpo negro, a de Einstein (1905) sobre o efeito fotoelétrico e a de Bohr (1913) sobre a teoria do átomo de Hidrogênio e concluiu que, entre as três contribuições, foi a de Einstein a que despertou a maior reação. A sua resposta para isso foi o que ele chamou de impacto da experiência. A fórmula do corpo negro cobria maravilhosamente bem os dados experimentais embora a dedução do próprio Planck não fosse convincente. Quanto à teoria de Bohr, essa permitia o confronto com os resultados experimentais da constante de Rydberg e a teoria de Bohr se mostrava notavelmente precisa. Quanto a Einstein, os resultados que permitiam medir o valor da constante de Planck a partir do efeito fotoelétrico somente foram possíveis com Millikan em 1914, ou seja, quase uma década após o seu trabalho de 1905.

Podemos acrescentar ainda um outro dado: um grande reforço em prol das idéias de Einstein viria somente em 1923-4 com o efeito Compton, ou seja, ainda mais uma década foi demandada para que mais uma vez as idéias de Einstein encontrassem retumbante corroboração. Acrescente-se mais uma circunstância histórica importante: já nessa época o paradigma de Copenhagen começava a se articular de maneira embrionária através do trabalho de Bohr, Kramers e Slater publicado em 1924 na revista inglesa Philosophical Magazine.

Mas Einstein vibrou com os resultados de Compton que corroboravam as suas idéias e refutavam o trabalho de Bohr, Kramers e Slater. No dia 20 de abril de 1924, Einstein es- creveu um artigo no periódico de Berlim Berliner Tageblatt no qual aparecia o seguinte trecho:

"O resultado positivo da experiência de Compton prova que a radiação se comporta como se fosse constituída por projéteis discretos de energia, não só em relação à transferência de energia, mas também em relação à Stosswirkung [transferência de momento]" (EINSTEIN apud PAIS, 1995: 492).

Tudo dava razão a Einstein. Mas muitas águas ainda iam rolar. Abraham Pais escreve a respeito:

"Os anos de 1923-4 marcam o fim da primeira fase do isolamento de Einstein em relação à teoria quântica. Mesmo assim, permaneceu um importante bastião de resistência ao fóton, centrado em Niels Bohr”. (PAIS, 1995: 492).

E aqui não basta a análise centrada sobre o problema da Realidade. O problema da Realidade também remete para outros problemas profundos e recorrentes em toda a história da filosofia e da filosofia das ciências: os problemas da Compreensibilidade e da Causalidade. Passemos, pois, a tecer algumas considerações sobre os problemas da Compreensibilidade e da Causalidade.

\section{Compreensibilidade e causalidade}

Os problemas da Compreensibilidade e da Causalidade são muito importantes e centrais na discussão das questões suscitadas pela teoria quântica e, deste modo, optamos aqui por tratá-los em conjunto. Como sabemos, trata-se de algo pertencente a uma longa tradição, a atitude segundo a qual os fenômenos tratados pela ciência devam ser concebidos como tendo lugar em um 'palco', ou seja, um espaço no qual os fenômenos se processam. Esses fenômenos também se processam no tempo e, deste modo, uma caracterização muito razoável dos mesmos (e aqui não estamos apenas nos restringindo à física, mas a qualquer que seja o tratamento de qualquer que seja o fenômeno do mundo natural) é a de concebê-los como tendo lugar no espaço e no tempo.

Muito teríamos o que escrever se quiséssemos tecer considerações sobre essas importantíssimas categorias conceituais, mas isso nos levaria demasiadamente longe. Deste modo teremos que pressupor muita coisa. No entanto, tornase quase irresistível que não venhamos a citar nomes como Descartes, Galileu e Newton. Newton, por exemplo, centrou tão enfaticamente a sua física nos conceitos de espaço e de tempo que os considerou como absolutos. A física de Galileu é também plena de relações espaço-temporais e Descartes, como sabemos, elegeu a extensão espacial como a característica precípua da matéria. Mas paremos por aqui a nossa referência a esses importantes autores.

Uma vez caracterizada a importância da descrição dos fenômenos no espaço e no tempo passemos para outra característica precípua das descrições dos fenômenos que é a relativa à Causa ou às Causas.

\footnotetext{
${ }^{16}$ De maneira amplamente consensual considera-se que o nascimento da física no Brasil tem origem com a chegada de Gleb Wataghin em 1934 na Universidade de São Paulo que então era criada.
} 
O estudo das causas tem uma longa história que remonta, pelo menos, há mais de dois mil anos. Aristóteles, por exemplo, estudou o assunto com muita profundidade e perspicácia. Ele dividiu as causas em quatro: a causa eficiente, a causa material, a causa formal e a causa final. Muito haveríamos o que discutir acerca desses conceitos, mas não o faremos aqui. No entanto, a fim de não passarmos em brancas nuvens, sem ao menos tecer breves considerações sobre um tema dessa importância, diremos que com a revolução científica do século XVII as causas finais foram completamente abolidas da física. As causas finais são aquelas que respondem a questões como: para que e para quem existe isso? Qual é o fim de existir isso? Qual é a finalidade disso? O mundo da ciência, após a revolução científica do século XVII, não se interessava mais por finalidades; era um mundo geométrico onde o que interessava eram as causas eficientes como as forças newtonianas; algum tempo depois a física conheceu grande complexidade e as causas formais passaram a ter uma grande importância, em larga medida, devido ao crescente desenvolvimento da própria abstração das teorias físicas. Para aprofundamento desta questão, ver (CARUSO \& MOREIRA XAVIER, 1994) e referências lá citadas.

Vejamos mais algumas considerações sobre o conceito de causa. Leibniz argumentou (LEIBNIZ, 1988: 237) ${ }^{17}$ que para a construção da matemática era necessário o princ ípio da contradição ou princípio da identidade, mas que para passar da matemática para a física seria necessário, além desse basilar princípio, também do princípio da razão suficiente segundo o qual nada existiria sem uma razão (ou seja, uma causa) pela qual isso fosse assim e não de outra maneira.

Deste modo, Leibniz considerou que a física, além de não poder incorporar contradições no seu interior, e deste modo, tal como a matemática, necessariamente ter que se ater ao princípio da identidade, também deveria, necessariamente, e desta vez com um pré-requisito adicional além daquele necessário para a construção da matemática, ser construída em cima de causas, ou seja, de princípios explicativos que fossem capazes de dar conta dos porquês de tais e tais coisas serem assim deste modo e não de outro, ou seja, a física deveria se ater tanto ao princípio da identidade quanto aos princípios causais.

As físicas de Descartes e de Leibniz são profundamente baseadas em princípios causais os quais são fortemente relacionados com as leis de conservação. (BASTOS FILHO, 1986; 1987; 1999b; AUSTRILINO et. al, 1995). A física de Newton embora se coadunasse com leis de conservação não as enfatizava; no contexto da física de Newton aquilo que se constituía na sua principal ênfase era o estudo da variação do movimento por meio de causas eficientes que agiam instantaneamente à distância.

A tradição longamente consolidada da física era aquela a qual, podemos dizer, se dedicava a uma descrição dos fenômenos no espaço e no tempo por meio de leis causais, sendo que as mais importantes dessas leis causais eram aquelas que expressam as leis de conservação. A conexão entre as leis de conservação e as propriedades invariantes do espaço e do tempo foram estabelecidas pela matemática Amalie Emmy Noether (1882 - 1935); trata-se de uma contribuição muito importante para a física teórica, pois conecta: a homogeneidade do tempo (atribuição de igual estatuto a quaisquer instantes de tempo) com a conservação da energia; a homogeneidade do espaço (atribuição de igual estatuto a todos os pontos do espaço) com a conservação do momento linear; e, a isotropia do espaço (atribuição de igual estatuto a todas as direções do espaço) à conservação do momento angular. Para maiores detalhes ver (BASSALO, 1990: 522-532) ${ }^{18}$.

Até 1924 era essa a tradição consolidada da física. E, se elegermos o marco inicial da mecânica quântica no ano de 1900, já havíamos percorrido um período de 24 anos de idéias quânticas. O corpo negro, o efeito fotoelético, a explicação einsteiniana para os desvios da lei dos calores específicos dos sólidos de Dulong e Petit, a teoria do átomo de Bohr, inclusive com os desenvolvimentos ulteriores devidos a Sommerfeld, o efeito Compton de 1923, entre outros fenômenos, eram todos inteligíveis dentro do contexto de uma concepção tal que admitisse que os fenômenos físicos têm lugar no espaço e no tempo e são descritos por meio de leis causais.

No curto período de 1924-1927 houve uma reviravolta radical na física. Foi proposta uma concepção diferente em relação àquela concepção que nos reportamos brevemente acima e, em larga medida, conflitante com essa tradição longamente estabelecida. As razões disso são enormemente complexas, e essa nova posição se tornou dominante por razões não triviais a ponto mesmo de ainda hoje serem estudadas por físicos de inclinações culturais, por historiadores e por filósofos da ciência. As razões não se reduzem a elementos meramente internos; de fato, os elementos externos seguramente desempenham papel de grande relevância no entendimento do porquê ter tido lugar esse desenvolvimento da física.

Evidentemente, a acusação de conservadorismo feita contra todos aqueles que reagiram a essa novíssima maneira de conceber a realidade não poderia ser feita de maneira séria posto que ninguém que tenha atitudes sérias perante o conhecimento deve aderir às novidades somente porque pessoas influentes e persuasivas estiveram a declarar o despontar de uma nova e radicalmente diversa concepção acerca da realidade. As adesões sérias devem se dar com reflexão, mas nunca por moda ou por simples persuasão. Espíritos independentes que são ao mesmo tempo grandes criadores como Einstein, Planck, de Broglie, Ehrenfest e Schrödinger não se deixaram persuadir. Schrödinger teve um momento de recaída, mas logo voltou às suas concepções iniciais. Ademais, exageros hiperbólicos dessa nova concepção poderiam ser nocivos para a educação e para a vida social dos indivíduos.

Acreditamos que nenhum desses espíritos independentes pode ser seriamente acusado de conservadorismo, mesmo porque a política de defender os seus próprios argumentos não com genuínos argumentos e sim mediante a desqualificação dos adversários com epítetos como esse de 'conservador' em nada ajuda para se compreender qualquer coisa que seja. Por isso consideramos um argumento tolo e vazio o que caracteriza Einstein como conservador.

Mas em que consistia essa reviravolta conceitual?

\footnotetext{
${ }^{17}$ Trata-se da Correspondência com Clarke, especificamente a segunda carta de Leibniz ou resposta à primeira réplica de Clarke.

${ }^{18} \mathrm{O}$ artigo de BASSALO tem o seguinte título: 'As Simetrias e as Leis de Conservação da Física'.
} 
O grande físico dinamarquês Niels Bohr que havia alcançado extraordinários resultados como os consubstanciados pela sua teoria do átomo de 1913 e o princípio da correspondência em 1923, resultados esses, convém ressaltar, inteiramente concebidos no contexto de uma física causal e espaço-temporal, foi o principal líder e mentor dessa nova concepção que contrastava enfaticamente com a tradição da física e inclusive com a tradição de sua própria física pregressa.

Neste estágio de nossa exposição é conveniente dar a palavra ao próprio Bohr que assim se expressou no dia 16 de setembro de 1927 na Conferência em homenagem a Alessandro Volta realizada em Como, Itália:

"A verdadeira natureza da teoria quântica [...] nos força a considerar a coordenação espaço-temporal e a exigência de causalidade, cuja união caracteriza as teorias clássicas, como características complementares, mas exclusivas, da descrição, simbolizando, respectivamente, a idealização da observação e da definição". (BOHR apud PAIS, 1995: 528).

Segundo Bohr, a tradição da física clássica era a de conceber os fenômenos no espaço e no tempo, fenômenos esses submetidos a leis causais e essa causalidade era ligada às leis de conservação; a mais importante dessas leis causais era a lei da conservação da energia. Outras leis muito importantes eram a conservação do momento linear, a conservação do momento angular, etc. Segundo Bohr, embora não fosse possível manter essa tradição no que diz respeito ao estudo dos fenômenos microscópicos segundo leis concomitantemente espaço-temporais e causais, dever-se-ia, por requisitos de correspondência entre os mundos microscópico e macroscópico, manter uma parte dessa tradição e modificar uma outra parte.

A parte que deveria ser mantida, segundo Bohr, era que tanto a abordagem espaço-temporal (descrição dos fenômenos microscópicos no espaço e no tempo) quanto a abordagem causal (descrição dos fenômenos microscópicos mediante leis causais) são ambas legítimas quando vistas per si. Ademais, elas devem ser usadas o que significa que uma parte da tradição clássica é decididamente mantida. No entanto, no contexto da física microscópica, elas, segundo Bohr, não poderiam ser usadas de maneira concomitante, tal como era o caso da física clássica. Vejamos pois as palavras do próprio Bohr:

“...I advocated a point of view conveniently termed "complementarity", suited to embrace the characteristic features of individuality of quantum phenomena, and at the same time to clarify the peculiar aspects of the observational problem in the field of experience. For this purpose, it is decisive to recognize that, however far the phenomena transcend the scope of classical physical explanation, the account of all evidence must be expressed in classical terms". (BOHR, 1961: 39) ${ }^{19}$

Bohr introduzia uma grande novidade que era uma mútua exclusão das descrições na física. Quando fosse implementada uma descrição rigorosamente espaço-temporal excluir-se-ia a descrição causal; do mesmo modo, quando fosse implementada uma descrição rigorosamente causal, excluir-se-ia, por conseguinte, a descrição espaço-temporal. Em suma, as duas descrições são válidas quando vistas per si, mas, necessariamente, se excluem mutuamente. Com o seu princípio de mútua exclusão que foi chamado de Princípio da Complementaridade, Bohr esperava dar mais abrangência à sua interpretação do assim chamado Princípio da Indeterminação de Heisenberg.

A mútua exclusão também teria a sua contrapartida no contexto do dualismo. Experimentos nos quais fosse implementado o aspecto corpuscular, excluiriam o aspecto ondulatório; de maneira análoga, experimentos nos quais fosse implementado o aspecto ondulatório excluiriam o aspecto corpuscular; assim como em relação a espaço-tempo e causa, também onda e corpúsculo seriam aspectos mutuamente excludentes, mas complementares no corpo do formalismo.

Einstein não gostou do Princípio da Complementaridade de Bohr. Em repetidas ocasiões ele se referia ao fato de que havia envidado muitos esforços para compreendê-lo, mas que não havia logrado êxito em sua empreitada. Popper, em um belo prefácio escrito em Londres no dia 10 de novembro de 1984 para o livro de Franco Selleri Le Grand Débat de la Théorie Quantique se referiu mesmo a uma lavagem cerebral ; Popper, na ocasião, assim se expressou:

"Le point le plus important, dans ce lavage de cerveau, c'est le probème de la compréhension. Une part de l'eseignement de Bohr - le maître à penser et le professeur d'Heisenberg, de Pauli et de presque tous les autres fondateurs de la mécanique quantique - consistait em ceci: ne cherchez pas à comprendre la mécanique quantique, elle est presque totalement incompréhensible. Bohr essaya d'expliquer cette incompréhensibilité, c'est-à-dire de rendre compréhensible l'incompréhensibilité. Son explication était que l'on ne peut comprendre que les situations qui ressemblent à celles auxquelles nous sommes accoutumés et que la seule physique à laquelle nous soyons accoutumés est la macrophysique. La microphysique est simplement autre; elle rompt avec la plupart de nos habitudes. C'est pourquoi nous sommes incapable de comprendre la microphysique et c'est pourquoi nous ne devrions pas

\footnotetext{
${ }^{19}$ O capítulo correspondente do livro de BOHR no qual a citação foi extraída tem o título: Discussion with Einstein on Epistemological Problems in Atomic Physics 1949, pp. 32-66. O excerto pode ser assim traduzido: "Eu argumentei em prol de um ponto de vista que denotei por "complementaridade" o qual englobasse os aspectos característicos da individualidade dos fenômenos quânticos e que, ao mesmo tempo, esclarecesse os peculiares aspectos do problema observacional no campo da experiência. Para alcançar esse propósito é decisivo que venhamos a reconhecer que, em que pese os fenômenos transcenderem o âmbito explicativo da física clássica, a explicação de toda evidência deve ser expressa em termos clássicos." (As ênfases em caracteres itálicos são do próprio BOHR)
} 
tenter de le faire". (POPPER, prefácio a SELLERI, 1986) ${ }^{20}$

Esta luminosa citação é um exemplo relativamente recente de um depoimento muito duro contra a lavagem cerebral capitaneada por Bohr acerca do problema da compreensibilidade na microfísica.

Sem dúvida, os problemas da microfísica exigem um refinamento muito grande das nossas faculdades intuitivas e o conceito de intuição pode assumir uma enorme gama de acepções, mas a reivindicação explícita de renuncia de compreensão e as muletas epistemológicas de "tornar compreensível o incompreensível" mediantes princípios ad hoc cuja aparente profundidade tudo leva a crer que é falsa, não constitui procedimento desejável para os que têm compromisso cognitivo genuíno. A esterilidade do Princípio da Complementaridade de Bohr confrontada com a fertilidade do Princípio da Correspondência do mesmo Bohr é algo que não pode passar despercebido.

Outrossim, haveria motivo para uma reivindicação assim tão pouco de acordo com a tradição científica?

O programa de 'tornar compreensível a incompreensibilidade' seria um programa de 'dissolução da causalidade' ou simplesmente a introdução de uma nova causalidade que se constituísse na procura da causa do incompreensível?

Havia uma competição entre os programas de pesquisa científica, respectivamente de Bohr e de Einstein. O Programa de Einstein era realista, racionalista e propugnava a compreensibilidade dos fenômenos no espaço e no tempo mediante leis causais; ademais para Einstein, tal como tivemos ocasião de tecer considerações na seção anterior, havia uma realidade objetiva e qualquer reivindicação de sua dissolução era verdadeiramente uma insensatez. E isso não porque ele fosse "conservador" mas porque seu espírito independente não o permitia ceder - pelo menos sem a devida reflexão - à persuasão e à moda.

Bohr, em 1924, no famoso trabalho escrito em colaboração com Kramers e Slater e publicado no periódico inglês Philosophical Magazine, havia sacrificado a lei de conservação da energia para eventos individuais; ele também, em outra ocasião, precisamente no episódio do neutrino, havia conjecturado acerca de uma possível violação da lei da conservação da energia que como já nos referimos, era um pilar importante das idéias de causalidade.

É algo notável que em ambas as ocasiões, como se diria na gíria, Bohr deu com os burros n’água. Os experimentos de Bothe \& Geiger (BOTHE \& GEIGER, 1925) e de Compton \& Simon (COMPTON \& SIMON, 1925,a,b) confirmaram, no contexto do Efeito Compton, a validade de leis causais em nível de eventos singulares na realidade microscópica, invalidando assim as conjecturas de Bohr lançadas no trabalho de 1924 publicado juntamente com Kramers e Slater na Philosophical Magazine.

Mas muita coisa acontecia: os tempos eram de ideologias muito pouco afetas ao racionalismo e à procura de leis causais; havia muito espaço para tendências como o existencialismo, a lebensphilosophie, etc. Deste modo, muitos outros argumentos de variados teores foram lançados para dar organicidade ao conjunto enorme de fenômenos. E esta história é muito complexa.

Em que medida tudo isso foi justificável e em que medida isso foi um exagero constitui assunto de interesse em relação ao qual muito ainda existe para se estudar com perspectivas de fertilidade.

E se nos for perguntado acerca das razões pelas quais a interpretação ortodoxa fora majoritariamente aceita diríamos que essas são de fato muito complexas. Podemos, em breves palavras, tecer algumas considerações.

Dentre as várias razões possíveis, podemos fazer alusão a três: (i) a escolha metodológica acerca de qual dualismo deveria ser assumido: se o dualismo da mútua exclusão associado a uma complementaridade no corpo do formalismo devido a Bohr ou se o dualismo baseado na coexistência em nível ontológico dos aspectos corpusculares e ondulatórios tal como propugnaram Einstein e de Broglie; ambas as escolhas metodológicas cobrem os fenômenos da dualidade; a escolha da mútua exclusão explicava os fenômenos de uma maneira contra-intuitiva, e a escolha da coexistência ontológica dos aspectos corpusculares e ondulatórios, embora os explicasse de uma maneira mais intuitiva, padecia da dúvida sobre o estatuto ontológico da onda vazia; a escolha majoritária recaiu sobre o que houvera sido proposto por Bohr; evidentemente aqui estamos super-simplificando pois nem todos os protagonistas eram dualistas; Schrödinger, por exemplo, defendia uma singularíssima concepção ondulatória; Landé aplaudiu, na época, o dualismo da mútua exclusão, mas décadas após tornou-se monista; (ii) uma segunda razão foi o importante teorema de Heisenberg que fora interpretado como incertezas de medidas por Bohr e não propriamente como uma relação de dispersão; (iii) a dificuldade de interpretar a função $\Psi$, solução da equação de Schrödinger, como um campo real no sentido ontológico e em analogia com os campos elétrico e magnético do eletromagnetismo de Maxwell; Bohr e colaboradores a interpretaram como uma entidade matemática, como uma amplitude de probabilidade em geral complexa, ou seja na forma $a+b i$ onde $a$ e $b$ são quantidades reais no sentido matemático e $i=(-1)^{1 / 2}$.

As razões aludidas são predominantemente internas, mas há as externas que também faremos breve alusão na próxima seção.

No que diz respeito ao programa causal da mecânica quântica é de bom alvitre fazer menção ao importante programa devido a David Bohm. Para uma versão mais recente dessa linha de trabalhos remetemos para (BOHM \& HILEY, 1993). Este importante programa tem sido objeto de estudo de colegas brasileiros (Ver ANGOTTI, 2002; FREIRE JR. et. al. 1994 e FRERE JR, 1999). Em colaboração com um colega estivemos estudando o 'modelo estatístico das esferas giratórias' (statistical ensemble of spinning spheres) que

\footnotetext{
20 “O ponto mais importante dessa lavagem cerebral é o problema da compreeñão. Uma parte dos ensinamentos de Bohr - o sábio e professor de Heisenberg, de Pauli e de quase todos os outros fundadores da mecânica quântica - consistia no seguinte: não procurar compreender a mecânica quântica, pois ela é quase totalmente incompreensível. Bohr tentou explicar essa incompreensibilidade, isto é, tentou tornar compreensível o incompreensível. Sua explicação era que somente poderíamos compreender situações que se assemelhassem às quais somos acostumados e que a única física da qual somos acostumados é a macroscópica. A microfísica é outra coisa. Ela destrói a maior parte daquilo que somos habituados. Esta é a razão pela qual não somos capazes de compreender a microfísica e também a razão porque não devemos tentar faze-lo." (Nesta nossa tradução, optamos por colocar a citação em caracteres itálicos; as ênfases que no texto original em francês aparecem em itálicos, aqui, na tradução em português, foram postas em caracteres, em negrito).
} 
lança mão da idéia de variável oculta. Trata-se de um modelo causal, e até mesmo determinista, que é capaz de reproduzir os resultados da teoria quântica de spin 1/2 (probabilidades, autovalores) mediante uma variável oculta $\underline{\lambda}$. Embora esse modelo não diga nada sobre a dualidade, ele tem enorme valor acadêmico, pois oferece um contra-exemplo legítimo ao teorema da impossibilidade de von Neumann, teorema esse que justamente sustentava a pretensa impossibilidade de se completar de maneira causal a mecânica quântica.

Ainda teríamos a dizer algo sobre temas como a compreensibilidade e a causalidade, mas o espaço já utilizado aqui nos convida a não ceder à tentação de prosseguir.

Passemos agora às nossas considerações sobre a influência do positivismo na física do século XX e alguns estranhos desdobramentos quanto a desenvolvimentos mais recentes.

\section{A influência do positivismo}

O pano de fundo cultural no qual se desenvolveu a teoria quântica é complexo e repleto de influências múltiplas e de diferentes teores. Foram muitas as correntes de pensamento que de uma maneira ou de outra influenciaram no seu desenvolvimento. Como se trata de uma teoria de múltiplas mãos, cujos pais fundadores eram pessoas de diferentes formações e vocações culturais, torna-se tarefa penosa individualizar apenas uma tendência filosófica como a mais importante. Por outro lado, poderíamos dizer que o desenvolvimento das idéias quânticas teve lugar em pelo menos duas ou três fases, a depender dos critérios que venham a ser utilizados.

Poderíamos considerar (e isso é matéria mais ou menos consensual) dois períodos respectivamente correspondentes a (1900-1924) e a (1924-1927); convencionou-se chamar o primeiro período de velha mecânica quântica se bem que a notação velha mecânica quântica é mais comumente referida aos desenvolvimentos do átomo de Bohr em 1913 e aos trabalhos sucessivos de Sommerfeld. Contudo, no sentido lato, é perfeitamente razoável considerar que no período de (1900- 1924) havia uma teoria quântica de caráter provisório, é bem verdade, mas filosoficamente de um espírito bastante diferente em relação à correspondente teoria quântica do período imediatamente sucessivo que foi o de (1924-1927) principalmente se nos ativermos ao fato de que foi precisamente neste último período que teve lugar a afirmação do paradigma de Copenhagen.

Correntes de teores os mais variados como o existencialismo, o misticismo, a filosofia da vida (lebensphilosophie), o realismo, o racionalismo, o irracionalismo, o positivismo, entre outras tiveram a sua influência.

Por exemplo, um famoso e bem documentado estudo de Paul Forman, (FORMAN, 1971; FORMAN, 1983) realizado há pouco mais de 30 anos mostra como o ambiente depressivo e pessimista do pós-guerra alemão - durante o período de 1918 a 1927 - inundou o espírito das pessoas com sentimentos anti-causais. Essa atmosfera foi tal que provocou uma grande hostilidade em relação à tradição realista e racionalista. A influência dessa atmosfera no seio da intelectualidade germânica foi de tal ordem que sua comunidade científica teve, quase forçosamente, de se acomodar gradativamente à corrente dominante dessas novas idéias.

Há outros estudos que apontam para uma forte influência do existencialismo dinamarquês. O pai de Niels Bohr se relacionava com intelectuais existencialistas. A idéia de mútua exclusão possivelmente tem origem na filosofia existencialista dinamarquesa.

Mas o caldeirão de influências é muito maior e mais intenso do que aquilo que poderia parecer à primeira vista. No presente estudo a nossa intenção é a de centrar mais a nossa atenção na corrente positivista que constitui uma das mais notáveis influências no que diz respeito à interpretação dominante da mecânica quântica.

E o que é o positivismo? Como a sua influência se manifesta na teoria quântica?

Ora, comecemos tentando situar alguma coisa a respeito do positivismo.

Tomemos, por exemplo, dois trechos do verbete positivismo de um importante dicionário de filosofia. Vejamos o primeiro desses trechos:

“....En efecto, si nos atenemos sólo a los rasgos formales podremos considerar como positivistas doctrinas habidas en cualquier período de la historia de la filosofía que se inclinen, por ejemplo, a considerar como objeto de conocimiento positivo sólo lo dado mediante los datos de los sentidos". (FERRATER MORA, 1975, Vol. 2, p. 455). ${ }^{21}$

Vejamos o segundo trecho:

“...podremos decir que el positivismo es una teoría del saber que se niega a admitir otra realidad que non sean los hechos y a investigar otra cosa que non sean las relaciones entre los hechos. En lo que toca por lo menos a la explicación, el positivismo subraya decididamente el cómo, y elude responder al qué, al por qué, y al para qué. Se une a ello, naturalmente, una decidida aversión a la metafísica, y ello hasta tal punto, que algunas veces se ha considerado este rasgo como el que mejor caracteriza la tendencia positivista". (FERRATER MORA, 1975: Vol. 2, p.456) ${ }^{22}$

Vejamos agora o que diz um outro dicionário de filosofia no texto do verbete positivismo precisamente na passagem em que Ranzoli tece considerações sobre o sistema filosófico de Comte:

\footnotetext{
${ }^{21}$ Vejamos a tradução para o português: "Efetivamente, se nos ativermos apenas aos aspectos formais poderemos considerar como positivistas as doutrinas existentes em quaisquer períodos da história da filosofia que tenham se inclinado, por exemplo, a considerar como objeto de conhecimento positivo apenas aquele fornecido mediante os dados dos sentidos.”

${ }^{22}$ A tradução correspondente para o português é: “...podemos dizer que o positivismo é uma teoria do saber que se nega a admitir outra realidade que não seja a dos fatos e a investigar outra coisa que não seja as relações entre os fatos. E no que toca pelo menos à explicação, o positivismo elimina decididamente $o$ como, e evita responder ao que, ao por que e ao para que. Une-se a isso, naturalmente, uma decidida aversão à metafísica, e isso a tal ponto, que algumas vezes esse aspecto foi considerado como o que melhor caracteriza a tendência positivista" (Aqui na tradução em português, as ênfases em caracteres em negrito correspondem às ênfases em itálico do texto original).
} 
“...ogni nostra conoscenza deriva dal senso cioè dall'esperienza; la scienza umana è scienza dei fenomeni, cioè del relativo; si deve quindi escludere ogni ricerca intorno alle sostanze, alle forze, all'origine e al fine delle cose; le scienze e la civiltà, prima di giungere al loro vero stato, cioè al positivo, passano per lo stato teologico, che è il più imperfetto, in cui i fenomeni vengono attribuiti alla volontà di enti sovrannaturali imaginari, e per il metafísico, in cui per rendersi ragione del mondo si ricorre ad entità astratte, cioè cause, forze e sostanze; dall'uno all'altro stadio le scienze passono tanto più presto quanto più sono astratte, quindi la classificazione delle scienze è fatta in base al loro grado di generalità; ai tre stadi della evoluzione scientifica corrispondono tre stadi dell'evoluzione sociale, e cioè il militare, il legale e l'industriale; nella società futura la scienza impererà sovrana sopra i destini dei popoli rigenerati, e il mondo sarà governato da uma corporazione di filosofi positivisti, ogni culto sarà sostituito dalla religione dell'Umanità, religione che, ammette um sacerdozio, una chiesa, un calendario e un' adorazione particolare". (RANZOLI, 1952: 885) ${ }^{23}$ (Aqui na tradução em português, as ênfase em caracteres em negrito correspondem às ênfases em itálico do texto original).

Vejamos mais uma referência genérica sobre o assunto. Na Enciclopédia Britânica podemos ler no verbete Positivism and Logical Empiricism, o seguinte texto: “...philosophical ideology and movement that arose toward the mid-19th century. It holds that (1) all knowledge of matters of fact is based upon the "positive" data of experience, to which the inquirer must adhere strictly; (2) there is a purely formal realm concerned with the relations of ideas - that of pure logic and mathematics; (3) all allegedly "transcendent" knowledge - of metaphysics, theology, and uncritical speculation - that radically goes beyond any possible evidence must be eschewed". (ENCYCLOPAEDIA BRITANNICA, 1979, Micropaedia, Vol VIII, p.150) ${ }^{24}$

Tendo em vista as últimas citações acima podemos ver que em sentido lato a corrente positivista, além de propugnar programaticamente a diretriz segundo a qual o pesquisador deve se ater aos dados imediatos da experiência, não se apega a questões como as que dizem respeito a causas. Somente fatos e relações entre fatos interessam aos positivistas. $^{25}$

No que diz respeito ao positivismo de Comte, a lei dos três estágios de evolução do conhecimento (teológico, metafísico e científico) em nada se assemelha ao complexo caldeirão da ciência de nossos dias. O pensamento científico de qualquer época que seja não pode ser separado nem "purificado" dos pressupostos metafísicos que lhe dão sustentação.

No que se refere à generalização da lei dos três estágios que os positivistas comtianos supuseram válida para o desenvolvimento do conhecimento e de sua passagem, por extensão, para o desenvolvimento da civilização, diríamos que os correspondentes estágios da evolução social (militar, legal e industrial) constituem algo muitíssimo pouco crível na

\footnotetext{
${ }^{23}$ A tradução correspondente para o português é: “...todo o nosso conhecimento deriva dos sentidos isto é da experiência; a ciência humana é ciência dos fenômenos, isto é, do relativo; deve-se portanto excluir toda a pesquisa acerca das substâncias, das forças, das origens e dos fins das coisas; as ciências e a civilização antes de alcançarem o seu verdadeiro estado, isto é o estado positivo, passam pelo estado teoðgico , que é o mais imperfeito, no qual os fenômenos são atribuídos à vontade de entes sobrenaturais imaginários, e pelo estado metafísico, no qual a fim de se explicar as coisas recorre-se a entidades abstratas, isto é, a causas, a forças e a substâncias; as ciências passam de um para outro estágio tão mais rapidamente quanto forem os seus níveis de abstração, portanto a classificação das ciências é feita com base nos seus graus de generalidade; aos três estágios da evolução científica correspondem três estágios da evolução social a saber, o militar, o legal e o industrial; na sociedade futura a ciência imperará soberana sobre o destino dos povos regenerados, e o mundo será governado por uma corporação de filósofos positivistas, todo culto será substituído pela religião da Humanidade, religião que admite um sacerdócio, uma igreja, um calendário e uma adoração particular."

${ }^{24}$ A tradução para o português é: “...ideologia e movimento filosófico que apareceu por volta de meados do século XIX. Essa corrente filosófica assevera que (1) Todo conhecimento que constitua matéria de fato é baseado sobre os dados "positivos" da experiência em relação aos quais o pesquisador deve rigorosamente se ater; (2) há um domínio puramente formal concernente às relações das idéias - da lógica pura e da matemática; e (3) todo conhecimento alegado como "transcendente" - metafísico, teológico ou especulação não crítica - que vai além de qualquer possível evidência deve ser evitado."

${ }^{25}$ Achamos por bem, inspirados pelas sugestões do árbitro deste artigo, fazer algumas ponderações acerca da relação dos positivistas com causas e/ou com explicações causais. Decerto, a rubrica positivismo compreende um guarda-chuva muito amplo. Muito comumente ela se refere a Comte (1789-1857), pois foi ele quem cunhou o nome ao escrever Cours de la philosophie positive. No entanto, se nos ativermos mais ao conteúdo do que simplesmente à notação podemos englobar como precursores, ou, até mesmo adeptos de correntes filosóficas positivistas no sentido lato do termo, filósofos da antiguidade como Protágoras, os Cirenáicos, os Epicuristas e os Empíricos. Também podem ser compreendidos neste guarda-chuva, por exemplo, a filosofia moderna do empirismo inclusive Hume (1711-1776). Numa caracterização generalista Klimke escreve que "El positivismo enseña que únicamente los hechos de la experiência externa e interna constituyen el fundamento y objeto del conocimiento cientifico, o dicho de outra manera, que nada podemos conocer fuera de los objetos de la experiência. Las essencias metafísicas de las cosas, la substancia, las causas, las fuerzas y potencias, Dios y el ultimo fin del hombre en consecuencia, escapan a nuestro saber" (KLIMKE, 1947: 638). Na mesma linha também argumenta o filósofo espanhol Julian Marías na sua conhecida Historia de la Filosofia; referindo-se, desta feita ao positivismo comtiano, escreve "El positivismo busca solo hechos y sus leyes. No causas ni princípios de las essencias o substancias. Todo esto es inaccesible” (MAŔ́AS, 1974: 339). Todos esses excertos são unânimes em reconhecer no positivismo uma recusa programática em relação à metafísica, às causas, à origem, às substâncias e às essências. No entanto, é possível, tendo em vista a abrangência desse guarda-chuva enfraquecer essa "recusa" programática. No que diz respeito a Hume, este recomendou um programa de modéstia na sua Investigação acerca do Entendimento Humano; ele escreveu: "Digo, pois, que mesmo depois que temos experiência das operações de causa e efeito, nossas conclusões desta experiência não estão fundadas sobre os raciocínios ou sobre qualquer processo de entendimento" (HUME, 1989: seção IV, $2^{a}$ parte, p. 81). Mais adiante, Hume concluirá sobre a conjunção causa/efeito o seguinte: "Esta conjunção pode ser arbitrária e acidental. Não há base racional para inferir a existência de um pelo aparecimento do outro" (HUME, 1989 seção V, $1^{a}$ parte, p. 86). Mais adiante Hume vai concluir que o princípio explicativo mais convincente não é o que resulta do entendimento e sim aquele que resulta do costume ou do hábito. "Este princípio é o costume ou o hábito" (HUME, op. cit., p. 87). É possível enfraquecer a questão da 'recusa', ou seja, não são propriamente as causas que são de fato recusadas, mas a atribuição das causas a um genuíno entendimento. Hume prefere atribuí-las ao costume ou ao hábito. Nesse sentido há um contraste notável com o princípio da razão suficiente de Leibniz.
} 
medida em que podemos ver a sua contradição flagrante com a experiência a mais consolidada. Hodiernamente assistimos, no seio de sociedades praticantes de ciência, a uma coexistência dos aspectos militares, legais e industriais e nada nos parece levar a crer que o aspecto militar se circunscreveria apenas ao estágio mais primitivo da evolução social para o qual a industrialização estaria distante.

Quanto ao mundo ser governado por uma corporação de filósofos positivistas com um culto universal, um sacerdócio, um calendário, etc, isso tudo nos parece algo muito pouco alvissareiro e pouco plural e até, em certo sentido, soa como um delírio. Esperemos que não seja a concretização de uma corporação que, pelo menos, não faça o culto do deus mercado. A idéia parece tão pouco simpática, e até mesmo tão pouco verossímil, que até provoca um sentimento de ironia.

No que diz respeito ao positivismo e ao empirismo lógico ou ainda ao positivismo lógico, essa corrente mais recente circunscrevia o seu universo de estudo àquilo que, segundo os seus seguidores, fizesse sentido e que, ademais, rigorosamente se ativesse aos dados da experiência. (Hoje em dia, provavelmente, usar-se-ia o termo observável). Tudo deveria estar sujeito à lógica e à matemática e, novamente, expulsar-se-ia, como inválidas ou destituídas de significado, todas as considerações que fossem "transcendentes", ou seja, enquanto diretriz geral deveria ser descartado tudo o que se ativesse à metafísica, à teologia e até às especulações não-críticas, o que deveria ser lido como especulações que se colocassem para além da experiência possível. Mas afinal, o que seria uma especulação não-crítica? Será que o atomismo especulativo e metafísico dos gregos seria tão fértil se eles seguissem as prescrições positivistas? E o conceito de espaço-tempo curvo de Einstein teria espaço no quadro das concepções positivistas? E o que dizer do sucesso dos conceitos de massa e de força da física newtoniana?

Uma outra possibilidade de se conceber as correntes positivistas no sentido lato do termo seria a de caracterizalas segundo as seguintes adoções filosóficas: (1) rígida separação entre sujeito e objeto ${ }^{26},{ }^{27}$; (2) neutralidade axiológica; (3) não admissão de elementos de naturezas $m i$ tológica, teológica e metafísica; e, (4) necessidade de se ater apenas aos observáveis, ou seja, se ater à necessidade de não se incorporar no seio das teorias científicas nada que não esteja ligado estritamente ao universo das coisas assim chamadas de observáveis. (BASTOS FILHO, 1999c).

Acreditamos que uma caracterização desse tipo tenha a sua importância, pois, levada a extremos, a separação rígida entre sujeito e objeto é uma coisa fora de propósito. Ora, se admitirmos que a ciência trata de fatos e de suas relações, o significado desses fatos não pode existir independentemente do sujeito, pois é o sujeito aquele que empresta significado aos fatos. Por mais que isso possa desagradar aos positivistas, não há significado de fatos em si e por isso os fatos não falam por si. Somos nós, através de nossas teorias, inatas ou não, que fazemos os fatos falarem. E a fertilidade com que eles falam depende da eventual riqueza ou pobreza de nossas teorias. Se os fatos falam eloquientemente é por que as teorias subjacentes que lhe deram voz são férteis em significado. É por isso que o famoso repto segundo o qual "os fatos falam por si" constitui-se num mito positivista que, infelizmente, continua a ter influência ainda hoje em muitos círculos de opinião, apesar dos esforços contrários de Bachelard, de Popper e de muitos outros autores. Há alguns anos, em um projeto de iniciação científica, foi desenvolvido um trabalho em colaboração no qual eram tecidos argumentos que mostravam que as mais simples idéias eram repletas de teoria e que, ademais, seria impossível estudar qualquer coisa que fosse analisando simplesmente fatos, pois esses somente são significativos se são lidos através de teorias. (BARBOSA FREIRE et. al., 1995).

Aqui, neste estágio de nossa discussão, é de bom alvitre que venhamos a esclarecer um ponto de grande importância que pode ser foco de muitos mal-entendidos e de perversas confusões conceituais. Infelizmente, já tivemos ocasião de ver muita confusão conceitual em torno dessas idéias e aqui seria de bom tom se envidássemos esforços no sentido de dirimí-las. Trata-se, por um lado, das complexas relações sujeito e objeto e, por outro, da necessidade de se caracterizar uma realidade objetiva. Einstein, por exemplo, foi um pensador de grande lucidez quanto a esse importante problema.

Como sabemos, muitos círculos culturais, infelizmente e erroneamente, tomam a necessidade de se conceber uma re-

\footnotetext{
${ }^{26}$ Esta caracterização deve ser flexibilizada principalmente tendo em vista o guarda-chuva amplo que o termo positivismo abriga. Reconhecemos que o árbitro de nosso trabalho tem uma boa parte de razão quando reivindica que uma eventual separação rígida entre sujeito e objeto apenas se adapte a alguns tipos de positivismo, mas não a todos eles. Evidentemente, o Bohr de 1913 (o Bohr da teoria do átomo de Hidrogênio) nada tinha de positivista. Se nos ativermos ao critério dos três estágios do positivismo de Comte, por exemplo, diríamos que alguém que postula algo tão distante do positivamente dado quanto 'um elétron que gira em torno de um núcleo' é uma pessoa que usa a imaginação (imagens pictóricas do átomo e ainda outras mais sutis) o que, segundo o que diria o critério de Comte, pertence à fase primitiva teológico-mística da inteligência. A imaginação é uma forma de participação do sujeito a fim de contornar o objeto e, sem dúvida, constitui uma forma de relação sujeito/ objeto que, a rigor, é irremovível em qualquer que seja a teoria. A citação de Bohr, sugerida pelo árbitro, segundo a qual "uma realidade independente no sentido físico ordinário não pode ser atribuída nem aos fenômenos, nem aos agentes da observação" (BOHR, 2000: 136), pode ser interpretada, sem dúvida, como um razoável espaço atribuído às relações sujeito / objeto. A própria teoria matricial de Heisenberg (de coloração positivista) ao atribuir relações entre intensidades das riscas espectrais e as matrizes hermitianas correspondentes, procede a uma ordenação dos fatos segundo critérios oriundos do sujeito que constrói a teoria correspondente. Logo, a rigor, não se pode aplicar a rígida separação entre sujeito e objeto. Logo, um positivismo extremo que propugne a rígida separação entre sujeito e objeto não pode ser sustentável.

${ }^{27}$ Há um outro aspecto. O historiador inglês, Carr em seu livro Que é História? argumenta contra a tradição empiricista positivista a qual , segundo ele, pode ser muito bem descrita pela expressão alemã "wie es eigentlich gewesen" que pode ser razoavelmente traduzida para o português como "o que realmente se passou ". Escreve ele: "Os positivistas, ansiosos por sustentar a sua afirmação da história como uma ciência, contribuíram com o peso de sua influência para este culto dos fatos. Primeiro verifique os fatos, diziam os positivistas, depois tirem suas conclusões. Na Grã-Bretanha, esta visão da história se adequava perfeitamente à tradição empirista que era a corrente dominante na filosofia britânica de Locke a Bertrand Russell. A teoria empírica do conhecimento pressup̃̃e uma separação completa entre o sujeito e o objeto. Fatos, como impressões sensoriais, impõem-se de fora, ao observador e são independentes de sua consciência. O processo de recepção é passivo: tendo recebido os dados, ele então atua sobre eles". (CARR, 1989: 13) Realmente teríamos que flexibilizar, mais uma vez o teor desta citação de Carr pois, a rigor, ela somente se adaptaria a casos extremos de positivismo. Ora, os fatos precisam de interpretação até mesmo para a sua escolha quanto à atribuição de pertinência e à atribuição de relevância; logo essa separação rígida entre sujeito e gem: objeto é a rigor insustentável. Evidentemente, a posição expressa por Carr tem valor enquanto crítica a uma concepção empirista positivista extrema de História.
} 
alidade objetiva como uma prescrição pertencente à adoção filosófica positivista e a interpretam, mais uma vez erroneamente e de maneira altamente infeliz, que a rígida separação positivista entre sujeito e objeto como algo equivalente à postulação da necessidade de se conceber a objetividade da realidade. Nada mais errado e fruto de uma ligeireza completa de reflexão. Vejamos por quê.

Efetivamente, em qualquer que seja a teoria científica a participação do sujeito é imprescindível mesmo porque sem o sujeito não haveria teoria científica alguma a ser criada. E essa é a maneira mais trivial e evidente de se conceber as relações sujeito e objeto. Todas as teorias científicas constituem um emaranhado de elementos que são escolhas do sujeito e, portanto, carregam consigo um conteúdo de arbitrariedade própria de tudo o que for concernente à criação humana; no entanto as teorias científicas também contêm, por outro lado, elementos objetivos que não dependem desse ou daquele sujeito particular. Este balizamento da realidade objetiva é absolutamente imprescindível, pois se não existisse tal balizamento não haveria distinção possível entre a criação científica e a criação poética que se permite extraordinário espaço de subjetividade. Ora, as teorias científicas enquanto produtos do espírito humano padecem de todos os defeitos e qualidades que todas as obras humanas contêm, mas elas devem necessariamente se distinguir de outras atividades criativas que contêm um espaço maior para a subjetividade como é o caso específico da poesia.

Por exemplo, na poesia, tal como já argumentamos alhures, é permitido em espaço de subjetividade de tal maneira elástico que ao poeta é permitido, ao seu inteiro arbítrio, misturar a representação da coisa pela coisa e deste modo expressar o real eloqüentemente, e nem por isso a realidade expressa deixa de ser menos significativa do que a correspondente expressão no que tange à atividade científica.

Ora, admitir que o sujeito tem um grande espaço no seio das teorias científicas não é equivalente a admitir que esse espaço seja hiperbolicamente grande, nem que ele possa realizar tudo que a sua imaginação lhe confere. Se o positivismo não permitia ao sujeito qualquer que fosse o espaço que não se ativesse rigidamente aos observáveis e por isso mantinha a rígida separação sujeito/objeto, o fato de se adotar o contrário, ou seja, o fato de se permitir ao sujeito que conjecture, fazendo entrar em suas considerações mitos e concepções metafísicas, não significa com isso que a realidade esteja dissolvida e evaporada. A sua criatividade pode correr à solta, mas é necessário se atribuir uma autonomia à realidade que é exatamente o seu caráter objetivo. E é justamente em relação a esse caráter autônomo da realidade objetiva que se deve balizar a invenção dos conceitos - que constitui um nobre espaço do sujeito - a fim de que essa realidade seja contornada.

A coisa é mais irônica do que se poderia pensar em um primeiro momento, pois foi exatamente a mesma corrente positivista que fazia apologia dos observáveis que também permitiu a entrada, pela porta dos fundos, do sujeito no corpo das teorias sobre a realidade microfísica.

"Paradoxalmente", mas somente paradoxalmente para os menos avisados, os positivistas que atribuem realidade apenas às entidades observáveis são os mesmos, ou pelo menos, muito próximos daqueles que atribuem realidade apenas quando essa é criada por medidas, pelo sujeito, senão por ambos.

No que concerne aos complexos desenvolvimentos da teoria quântica, a influência do positivismo se fez notar muito claramente na crítica de Heisenberg à teoria atômica de Bohr de 1913. Como sabemos, a teoria atômica de Bohr teve um sucesso muito grande e foi repleta de belos resultados, entre os quais, e aqui nos reportaremos a apenas um deles: o resultado segundo o qual a teoria foi capaz de expressar a constante de Rydberg em termos de três constituintes basilares da física atômica que são a massa do elétron, a carga do elétron e a constante de Planck, sendo que esta última fazia a sua gloriosa aparição pela terceira vez ${ }^{28}$ se considerarmos que a primeira foi a de 1900 devido aos trabalhos de Planck sobre o corpo negro e a segunda foi o trabalho de Einstein sobre o efeito fotoelétrico. Mas retornemos à crítica de Heisenberg.

Em que consistia, de fato, a crítica de Heisenberg à teoria atômica de Bohr? Ora, é conveniente ressaltar que apesar da teoria atômica de Bohr ter sido uma árvore que deu excelentes frutos, também começou a se exaurir devido à complexidade crescente dos fenômenos tratados como, por exemplo, o efeito de Zeeman anômalo que, como se sabe, requeria a introdução do conceito de spin em física.

Ora, a crítica de Heisenberg consistia no seguinte: uma teoria atômica conseqüente deve se ater rigorosamente aos observáveis, isto é, deve se ater a grandezas que possam ser controladas em laboratório. Como prescrição metodológica dever-se-ia evitar a incorporação, no seio das teorias científicas, de entidades que não tivessem contrapartida direta com os dados imediatos da experiência. Ora, a teoria atômica de Niels Bohr de 1913 lançava mão de recursos como órbitas do elétron em torno do núcleo, raios orbitais, velocidades orbitais do elétron e outras do gênero. Como sabemos, essas não eram diretamente observáveis e Heisenberg viu nisso um defeito que deveria ser corrigido. Heisenberg considerava que uma teoria mais conseqüente acerca da realidade atômica deveria se ater exclusivamente a grandezas observáveis como, por exemplo, as freqüências emitidas pelos átomos, as intensidades da luz exibidas nos espectros, etc.

A mecânica matricial de Heisenberg, também levada a cabo devido à colaboração de Heisenberg com Max Born e Kramers, situava-se no contexto de um programa de pesquisa científico de coloração positivista no qual definia-se o problema - o oscilador harmônico simples, por exemplo procedia-se a construção das matrizes associadas às grandezas físicas como, por exemplo, a matriz coordenada, a matriz quantidade de movimento, a matriz energia, e assim por diante, todas elas, em conexão direta com os assim chamados observáveis.

Este desenvolvimento no qual o espírito de coloração positivista era o seu principal pano de fundo haveria de se contrastar com o espírito realista da mecânica ondulatória de Schrödinger para a qual, justamente a solução da equação fundamental - a equação de Schrödinger - se via em claras dificuldades. Era de fato uma tarefa hercúlea interpretá-la no contexto de uma concepção realista de ciência.

No entanto, Heisenberg tentou justificar a sua atitude dizendo que havia se inspirado em Einstein por ocasião de seu

\footnotetext{
${ }^{28}$ Ou pela quarta vez se optarmos em considerar que a teoria dos calores específicos de Einstein em 1907 tenha sido a terceira vez.
} 
famoso trabalho de 1905 sobre a relatividade restrita. Vejamos a seguinte e interessantíssima passagem:

"I pointed out [to Einstein] that we cannot, in fact, observe such a path [of an electron in an atom]; what we actually record are frequencies of the light radiated by the atom, intensities and transition probabilities, but no actual path. And since it is rational to introduce into a theory only such quantities as can be directly observed, the concept of electron path ought not, in fact, to figure in the theory. To my astonishment, Einstein was not at all satisfied with this argument. He thought that every theory in fact contains unobserved quantities. The principle of employing only observable quantities simply cannot be consistently carried out. And when I objected that in this I had merely been applying the type of philosophy that he, too, had made the basis of his special theory of relativity, he answered simply: "Perhaps I did use such philosophy earlier, and also wrote it, but it is nonsense all the same". (HEISENBERG, 1983: 114 apud WEINBERG, 1994: 180) ${ }^{29}$.

Vejamos alguns comentários. O protesto de Einstein segundo o qual é impossível construir uma teoria física numa aderência restrita e exclusiva aos observáveis fez eco. Por exemplo, em um de seus últimos artigos, J. S. Bell (BELL, 1990) referindo-se a Einstein escreveu: Einstein said that it is theory which decides what is 'observable' 30 .

Uma simples virada de cabeça a fim de refletir sobre o assunto nos mostra que o programa positivista, quando levado a extremos, sequer constitui-se em algo sustentável. Ora, a mera ordenação dos fatos requer, necessariamente, critérios que transcendam os fatos. Logo em qualquer teoria em que os fatos sejam ordenados (e este é rigorosamente o caso de qualquer teoria) há, necessariamente a presença de elementos que são metafactuais. ${ }^{31}$

Acreditamos que a batalha contra o positivismo em física não deveria se dar no extremo em que ele não é sustentável, pois assim não haveria batalha alguma a ser travada. A batalha deve ser travada pelos seus flancos mais duros, por exemplo, pelo lado do combate à interpretação operacionalista da função de onda da mecânica quântica onde toda a realidade parece reduzida às operações de medida. J. $\mathrm{S}$. Bell no mesmo artigo acima referido (BELL, op. cit.) pergunta: Why this aversion to 'being' and insistence on 'finding'? ${ }^{32}$

Mas aqui não entraremos em detalhes, tal como o fizemos em outra ocasião (BASTOS FILHO, 1999a ; 2002a) pois isso nos levaria demasiadamente longe. Passemos a outro flanco importante da luta contra o positivismo o qual, em larga extensão, está relacionado com este já referido. Tratase do importante tema da compreensibilidade.

Schrödinger, nas suas palestras proferidas nos dias 24, 26, 28 e 31 de maio de 1948 (Shearman Lectures) cujos textos foram consubstanciados no seu livro Nature and the Greeks assim se expressou:

"Though the positivist view ostensibly contradicts the 'understandability of Nature', it is certainly not a return to the supertitious and magical outlook of yore; quite the contrary, from physics it expels the notion of force, the most dangerous relic of animism in this science. It is a salutary antidote against the rashness with which scientists are prone to believe that they have understood a phenomenon, when they have really only grasped the facts by describing them. Yet even from the positivists' point of view one ought not, so I believe, to declare that science conveys no understanding. For even if it be true (as they maintain) that in principle we only observe and register facts and

\footnotetext{
${ }^{29} \mathrm{~A}$ tradução correspondente em português é: Eu fiz notar [a Einstein] que nós não podemos, de fato, observar essa trajetória [de um elétron em um átomo]; o que nós podemos medir, de fato, são as frequiências da luz emitida pelo átomo, as intensidades e as probabilidades de transição, mas nunca qualquer que seja a trajetória. E desde que isso seja assim, é então mais racional proceder a introdução na teoria apenas dessas quantidades que podem ser diretamente observadas e, desta maneira, o conceito de trajetória eletrônica não deve aparecer na teoria. Ele, no entanto, pensa que toda teoria contém quantidades não observáveis. O princípio de empregar apenas quantidades observáveis simplesmente não pode ser levado a cabo de maneira consistente. E quando opus-me alegando que eu houvera posto em prática o mesmo tipo de filosofia que ele houvera também posto e que serviu de base à sua teoria da relatividade restrita, ele simplesmente respondeu: "Talvez eu tivesse feito uso dessa filosofia antigamente, e também tenha escrito isso, mas de qualquer forma é uma besteira."

30 "É a teoria que decide o que é observável".

${ }^{31}$ Cumpre aqui uma nota explicativa que consideramos de essencial importância. O árbitro de nosso trabalho sugere a omissão do parágrafo acima do texto central a partir do qual foi puxada esta nota de rodapé. Não estamos de acordo com isso pois, além de julgarmos o parágrafo significativo, cremos que estamos diante muito mais de um mal-entendido que precisa ser dirimido do que propriamente de uma divergência. Ele concorda com a segunda frase do parágrafo segundo a qual a mera ordenação dos fatos requer, necessariamente, critérios que transcendam os fatos e escreve que "a afirmação é correta e claramente aceita pelos positivistas mesmo os mais radicais (Hume estudou bem a questão)" e argumenta, outrossim, que "ao negar isto, o autor reconstrói as doutrinas positivistas de maneira muito simplista e errônea". Ora, se nos ativermos à primeira frase do parágrafo, veremos que estamos nos referindo ao programa positivista quando levado a extremos, logo estamos nos referindo a casos extremos desse guarda-chuva amplo que abriga, no sentido lato, as correntes positivistas. Bacon é um exemplo de caso extremo quando recomenda a quem quiser ter acesso ao conhecimento que proceda a uma purificação de seu intelecto de tal maneira a se livrar de todos os ídolos de maneira semelhante a quem quiser "...ter acesso ao reino dos céus, ao qual não se permite entrar senão sob a figura de criança" (BACON, 1988, Livro I, Aforismo LXVIII, pp. 37-38). O que Bacon queria dizer com essa metáfora é que quem for puro de espírito (ou seja, quem não carregar teoria prévia) pode alcançar o verdadeiro conhecimento. Já Comte (o mais emblemático dos positivistas) não se enquadra propriamente neste caso extremo. Comte, por exemplo, escreveu: "Todos os bons espíritos repetem desde Bacon, que somente são reais os conhecimentos que repousam sobre fatos observados. Essa máxima fundamental é evidentemente incontestável se for aplicada, como convém, ao estado viril de nossa inteligência. Mas reportando-nos à formação de nossos conhecimentos, não é menos certo que o espírito humano, em seu estado primitivo, não podia nem devia pensar assim. Pois, se de um lado toda teoria positiva deve necessariamente fundar-se sobre observações, é igualmente perceptível que, para entregar-se à observação, nosso espírito precisa de uma teoria qualquer" (COMTE, 1988: 5). Aqui nos deparamos com algo irônico pois Comte atribui a necessidade de teoria prévia ao estado primitivo. Acreditava ele, muito infelizmente, e erroneamente ao nosso ver, que no estado assim chamado de positivo, as teorias prévias pudessem ser dispensadas.

32 "Por que esta aversão por 'estar' e insistência em 'encontrar'?"
} 
put them into a mneumotechnical arrangement, there are factual relations between our findings in the various, widely distant domains of knowledge, and again between them and the most fundamental general notions (as the natural integers $1,2,3,4 \ldots$ ), relations so striking and interesting, that for our eventual grasping and registering them the term 'understanding' seems very appropriate”. (SCHRÖDINGER, 1996: 91-92) $)^{33}$

É também sobre o problema da compreensibilidade, ou ainda, sobre a profundidade com a qual centramos a nossa luta contra o positivismo no importante problema da compreensibilidade e da inteligibilidade do mundo, é que distinguimos o compromisso realista e racionalista daquele compromisso peculiar à adoção filosófica do positivismo em física.

Na capa de trás de um dos mais recentes livros de Selleri encontramos o significativo e provocante texto que bem retrata o que aludimos acima. Vejamos pois:

"Il libro è in polemica con le tendenze positivistiche del Novecento che hanno cercato di eliminare dalle scienze naturali la volontà di affrontare correttamente i segreti della natura". (SELLERI, 2001: texto de capa de trás) ${ }^{34}$

E foi também seguindo esta diretriz epistemológica, otimista e cheia de entusiasmo, que mostramos (BASTOS FILHO, 1994: 485-492) - e até então consideramos os nossos argumentos convincentes e ninguém ainda nos convenceu do contrário - que seguindo a linha do dualismo objetivo a la Einstein e a la de Broglie é possível tornar perfeitamente inteligíveis os resultados das experiências de pensamento que Feynman (FEYNMAN, 1965, Cap. 5) propõe para as partículas de spin-um (spin one particles) com massa de repouso não nula.

Preferimos apostar na adoção epistemológica da inteligibilidade do mundo do que na resignação instrumentalista a la Stapp ao interpretar o pensamento de Bohr (não o Bohr do Princípio da Correspondência e sim o Bohr do Princípio da Complementaridade):

"According to Niels Bohr quantum theory must be interpreted, not as a description of nature itself, but merely as a tool for making predictions about observations appearing under conditions described by classical physics". (STAPP, 1987: 255$)^{35}$
E essa redução de uma teoria fundamental a mero instrumento, tão decantada em prosa e verso como a maneira mais avançada de se conceber a realidade quântica, não seria de fato conservadora e receosa do enfrentamento dos genuínos desafios cognitivos?

Talvez Gell-Mann tenha respondido parcialmente a esta questão quando declarou:

"Niels Bohr brainwashed a whole generation of physicists into believing that the problem had been solved fifty years ago" (GELLMANN, 1979: 29 apud STAPP, 1987:257)

E deixando esta declaração apimentada que foi reservada para uma ocasião solene onde, talvez, se pudesse fazer um pouco mais de exercício de sinceridade, encerramos a presente seção. ${ }^{36}$

\section{Discussão e considerações finais}

É chegada a hora de organizarmos tudo o que foi discutido até então neste trabalho integrando o seu conteúdo, e ainda acrescentando mais alguns poucos elementos os quais julgamos que sejam imprescindíveis para a construção de um todo harmonioso e articulado.

Como vimos, levantamos alguns dos problemas epistemológicos suscitados pela teoria quântica. Três problemas foram escolhidos, a saber, - o da Realidade, o da Compreensibilidade e o da Causalidade - bem como discutidas algumas das conexões entre eles. Vimos também alguns aspectos da grande divergência entre influentes pensadores do século XX como Einstein e Bohr acerca desses problemas e a influência do positivismo no contexto da afirmação do paradigma dominante de interpretação da mecânica quântica que é a interpretação de Copenhagen.

Logo no começo do presente trabalho referimo-nos à grande complexidade e inconclusão do debate sobre a teoria quântica e até mesmo usamos as conhecidas expressões de 'Torre de Babel', 'Diálogo de Surdos' e de 'Pântano Conceitual'. Apesar de tudo, tal com colocamos, faz-se necessário reconhecer o enorme passo à frente no conhecimento da realidade física proporcionado pela teoria quântica.

Um dentre os muitos sentidos em que o termo 'complexidade' encontra acolhida no contexto do debate sobre a teoria quântica é o da epistemologia da complexidade de Gaston Bachelard, tanto no que diz respeito à inversão do problema da intuição em Descartes (o qual consubstanciamos em citações do próprio Bachelard exibidas em notas de

\footnotetext{
${ }^{33}$ Trata-se de um excerto do livro Nature and the Greeks, precisamente no capítulo VII de título What are the Special Features? . Em português o excerto pode assim ser traduzido: “ Ainda que o ponto de vista positivista contradiga a 'inteligibilidade da Natureza', ele certamente não significa um retorno à visão supersticiosa e mágica de outrora; bem ao contrário, essa visão expulsa da física a noção de força, a mais perigosa relíquia do animismo nesta ciência. Ela é um antídoto salutar contra a precipitação com a qual os cientistas estão propensos a acreditar que entenderam um fenômeno quando o que realmente fizeram foi entende-lo ingenuamente mediante uma mera descrição dos mesmos. Além disso, a partir do ponto de vista positivista não se deve declarar, assim eu acredito, que a ciência não conduza à compreensão alguma. Mesmo que isso fosse verdade (como eles asseveram) que, em princípio, nós somente observamos e registramos fatos e os pomos num arranjo mneumotécnico, existem relações factuais entre nossas descobertas em tão variados e largamente distantes domínios do conhecimento, e novamente entre eles e as mais atraentes e interessantes noções gerais fundamentais, que o nosso rudimentar entendimento e o registro dos mesmos parecem se adaptar ao termo 'compreensão'."

34 "O livro se apresenta em polêmica com as tendências positivistas do século XX que procuraram eliminar das ciências naturais a vontade de enfrentar corretamente os segredos da natureza."

35 "De acordo com Niels Bohr, a teoria quântica deve ser interpretada, não como uma descrição da natureza em si própria, e sim como um instrumento para fazer previsões acerca das observações aparecendo sob condições descritas pela física clássica."

36 "Bohr procedeu uma lavagem cerebral numa geração completa de físicos fazendo-os crer que o problema havia sido resolvido há cinqüenta anos."
} 
rodapé) quanto em relação ao necessário, e diria até mesmo inesgotável, diálogo entre a teoria e a experiência.

Se o ser não é mais imediatamente captado de maneira clara e distinta, pois a doutrina das naturezas simples e absolutas é uma ilusão, então faz-se necessário que venhamos a recorrer às relações necessariamente complexas ensejadas pelo diálogo - em certo sentido interminável - entre teoria e experiência. E aqui não poderíamos resistir à tentação de citar mais o seguinte excerto de Bachelard, sem esquecer que este autor escreve por volta de 1934-5:

"Seja qual for o ponto de partida da atividade científica, essa atividade não pode convencer plenamente, a não ser abandonando o terreno de base: se experimenta, precisa raciocinar; se raciocina, precisa experimentar. Toda aplicação é transcendência. Mostraremos que na mais simples atividade científica pode-se captar uma dualidade, uma espécie de polarização epistemológica que tende a classificar a fenomenologia sob a dupla rubrica do pitoresco e do compreensível; em outras palavras, sob a dupla etiqueta do realismo e do racionalismo. Se, a propósito da psicologia do espírito científico, pudéssemos colocar-nos precisamente na fronteira do conhecimento científico, veríamos que o que ocupou a ciência contemporânea foi uma verdadeira síntese de contradições metafísicas. Contudo, o sentido do vetor epistemológico parece-nos bem nítido. Vai seguramente do racional ao real e não, ao contrário, da realidade ao geral, como o professaram todos os filósofos de Aristóteles a Bacon”. (BACHELARD, 1988: 4).

Ora, se um dos aspectos mais relevantes da epistemologia complexa de Gaston Bachelard constitui um novo espírito científico que tem como características precípuas as necessidades recíprocas e indissolúveis tanto da experiência raciocinar quanto do raciocínio experimentar, e, ademais, que este novo espírito científico constitui um entrelaçamento complexo de metafísicas contraditórias, mas que o vetor epistemológico vai sempre na direção do racional para o real, então vemos muito claramente uma aproximação entre essa epistemologia complexa de Bachelard e a epistemologia popperiana do racionalismo crítico que adota que o método da ciência é o das conjecturas e refutações (POPPER, 1982).

Faz-se mister ressaltar que tanto Bachelard quanto Popper recusam o empirismo e o racionalismo empedernidos, mas ambos são, a um só tempo, empiristas e racionalistas de maneira entrelaçada e complexa. O diálogo teoria/experiência, tanto em Bachelard quanto em Popper, é interminável e inesgotável. Para Popper, por exemplo, conforme a sua bem conhecida inspiração a la Xenófanes, nunca saberemos se as nossas teorias são verdadeiras por mais amplamente corroboradas que sejam; logo, para Popper há o não eliminável caráter conjectural de qualquer que seja a teoria científica, ou dito em palavras ligeiramente diferentes, as teorias científicas são eternamente conjecturais. Para Popper somente podemos saber quando as nossas teo- rias são falsas mas nunca quando são verdadeiras. No entanto, pode-se introduzir mais um elemento de complexidade em relação ao falsificacionismo. Chalmers escreve a propósito o seguinte acerca das limitações do falsificacionismo:

"As teorias não podem ser conclusivamente falsificadas porque as proposições de observação que formam a base para a falsificação podem se revelar falsas à luz de desenvolvimentos posteriores". (CHALMERS, 1999: 94).

E neste preciso momento de nossa exposição julgamos fazer parte da organização e sistematização do que aqui refletimos, além da aproximação entre as epistemologias, respectivamente, popperiana e bachelardiana, também da entrada em cena do importante problema acerca do caráter das assim chamadas experiências cruciais. Numa instância imediatamente sucessiva argumentaremos também em prol da entrada em cena da idéia lakatosiana dos programas $\mathrm{ci}$ entíficos de pesquisa.

Em conexão com a expressiva citação de Chalmers acima podemos evocar um exemplo emblemático da história da ciência. Tomemos um exemplo da óptica do século XIX. Vejamos o seguinte texto de um conhecedor moderno do assunto:

"Em 1850, o físico francês Jean-BernardLéon Foucault (1819-1868) [FOUCAULT, 1850] usando uma sugestão de Arago, apresentada em 1842, determinou a velocidade da luz tanto no ar quanto na água. Nesse mesmo ano de 1850, Fizeau e L. Breguet [FIZEAU \& BREGUET, 1850], também seguindo a mesma sugestão de Arago, calcularam a velocidade da luz no ar e na água. Em ambas as experiências, a velocidade da luz na água era menor do que no ar, resultado esse, portanto, favorável à teoria ondulatória". (BASSALO, 1990: 597 e 602; BASSALO, 1989).

Se fossemos pessoas de meados do século XIX e se houvéssemos eleito as experiências de Foucault e de Fizeau como 'experiências cruciais' ou seja como experimenta crucis, no sentido mesmo de uma 'decisão definitiva' que constituísse um veredicto final para a pergunta (a luz é onda ou corpúsculo?) a resposta teria sido, sem qualquer sombra de dúvida, a seguinte: 'a luz é onda e deste modo estão "definitivamente" descartadas todas as teorias corpusculares da luz inclusive a teoria corpuscular da luz de Newton'. Na época, um veredicto do gênero foi confirmado por outras experiências. Para maiores detalhes ver (BASSALO, 1990: 602, especificamente a referência $\mathrm{n} \%$ 87).

Mas neste exato momento não poderíamos deixar de parafrasear o famoso autor de Hamlet e dizer que a natureza e em especial a luz - tem muito mais sutilezas do que sonhariam as nossas vãs ciência e filosofia! Aqui caberia também a famosa frase de Einstein que foi pronunciada por ocasião de um outro episódio da história da ciência:

37 "O Senhor é sutil, mas não malicioso". 
"Raffiniert ist der Herr Gott, aber boshaft ist er nicht". (EINSTEIN, apud PAIS, 1995: epígrafe ao livro) ${ }^{37}$

E na interpretação que o próprio Einstein emprestou à sua aparentemente enigmática frase:

"Die Natur verbirgt ihr Geheimnis durch die Erhabenheit ihres Wesens, aber nicht durch List". (EINSTEIN apud PAIS, 1995: epígrafe ao livro) $)^{38}$

Mas voltemos à nossa questão: eram as experiências de Fizeau e Foucault cruciais ou não?

Como sabemos, uma boa resposta para esta pergunta não pode se reduzir a um mero SIM ou NÃO, pois isso seria, quase equivalente, a admitir um realismo ingênuo. Por outro lado não se pode descambar para um outro extremo ao se duvidar de todo e qualquer controle experimental. É necessário considerar que no contexto do intenso e complexo diálogo teoria/experimento ele desempenha um papel imprescindível. Ora, há alguns aspectos para os quais se pode admitir - provisoriamente ou não - algum grau em que os experimentos sejam cruciais. No entanto, jamais a característica de ser crucial será esgotada sob todo e qualquer aspecto, pois os grandes problemas são complexos, recorrentes, remetem para outros ainda mais complexos e a tese da inesgotabilidade nos ensina que não há explicações últimas pois a melhor explicação sempre carece de explicações ulteriores e mais elaboradas.

De fato, o conceito de experimento crucial não pode ser visto independentemente do referencial teórico com o qual cercamos a realidade. E se a realidade é objetiva, são as nossas teorias-rede (e com elas o conjunto de pressupostos com os quais nos aproximamos do real) que vão nos dizer quais aspectos do real podemos captar. Longe do ideal positivista dos 'fatos falarem por si' que separa drasticamente sujeito e objeto, as nossas teorias-rede - construídas pelo sujeito, e por isso contendo, por um lado, as vicissitudes do sujeito, mas, por outro, pressupondo uma realidade objetiva com larga autonomia em relação a ele - são justamente aquelas que nos permitirão obter tais e tais eventuais respostas e não outras que estão fora do universo de possibilidades do poder explicativo dos referenciais teóricos utilizados. Logo o grau em que uma teoria pode ser considerada crucial - em certos sentidos, mas não em todos - dependerá do referencial teórico utilizado e tudo isso respeita o conceito de objetividade da realidade. É necessário considerar um diálogo sutil com a realidade diferentemente daquele pressuposto por um realismo ingênuo ou de qualquer outra posição que ainda tenha a ilusão de ver "as coisas como elas são" 39 .

Obviamente, e disso ninguém hoje duvidaria, o referencial teórico que deu substrato para que o veredicto de experiência crucial fosse dado para as experiências de Fizeau e de Foucault não pode ser aplicado nem ao efeito fotoelétrico nem à dispersão elétron-fóton gama de que trata $o$ efeito Compton. Logo, este emblemático exemplo histórico
- mas não somente ele como muitos e muitos outros - nos convidam a concluir que o diálogo teoria/experimento é absolutamente necessário e não se adapta a sínteses apressadas e muito menos a afogadilhos e modismos.

Mamone Capria, por exemplo, se refere com destaque à crítica que Pierre Duhem (DUHEM, 1914) fez ao conceito de experiência crucial. Mamone Capria considera mesmo "profunda e em substância definitiva a crítica de Duhem à idéia de experimento crucial"(MAMONE CAPRIA, 1999a: 323; 2002a: 285). Em outro momento (MAMONE CAPRIA, 1999b: 44-46; 2002b, 42-44) Capria escreve mais longamente sobre os argumento de Duhem acerca do que esse último autor chamou de "impossibilidade do experimentum crucis". Remetemos o leitor para esses textos.

Deparando-nos com a grande e crescente complexidade da ciência dos tempos de agora presenciamos cada vez mais que os resultados experimentais são lidos através de redes de teorias que sua vez são lidas através de outras redes de teorias, e de pressupostos que formam redes de hipótese auxiliares e/ou ad hoc, e assim por diante. Facilmente podemos concluir que tudo isso se afasta de muitos anos-luz da maneira baconiana de conceber a ciência. Também se afasta da ilusão cartesiana de captação das naturezas simples e diretamente através da intuição de clareza e distinção, embora em quaisquer situações que sejam são sempre desejáveis a clareza de exposição e a distinção de idéias e conceitos. A Cosmologia, a Física de Partículas e muitos outros campos vivem essa crescente complexidade.

Mas há muitos outros elementos de complexidade. Um deles é o papel desempenhado pela contradição. Sem querer fazer qualquer apologia da contradição - pois entendemos que devemos envidar esforços para superá-las - haveremos de reconhecer que o próprio empreendimento científico nos mostra que é possível progredir mesmo em bases inconsistentes e nisso, afiançamos, não constitui repto algum em prol da irracionalidade. Condenamos a irracionalidade programática. No entanto, é muito importante se ter em mente que trabalhar provisoriamente sobre bases inconsistentes pode fazer parte de um programa de pesquisa racional e fértil. Com o fito de aprofundar o assunto ver (LAKATOS, 1979: 176, nota de rodapé $\mathrm{n}^{0} 202$; KLINE, 1980; KLINE, 1985).

Lakatos defendeu o ataque devastador de Popper contra Hegel, pois Hegel exagerou em grau hiperbólico ao elevar a contradição ao estatuto de virtude suprema. Mas Lakatos também atacou o falseacionismo ingênuo de Popper consubstanciado, dentre outras coisas, na recomendação para que os cientistas abandonassem as suas teorias já diante da primeira inconsistência. Insiste Lakatos, evocando até mesmo a história da matemática e também a história da teoria do átomo de Bohr, que é possível fazer progressos científicos notáveis mesmo sobre a base de fundamentos inconsistentes. E é importante que se reafirme que isso não constitui namoro algum com teses que pregam a irracionalidade, pois esse programa de pesquisa tem uma estratégia racional.

\footnotetext{
38 "A Natureza não esconde seus segredos por malícia, mas sim por causa da própria altivez."

${ }^{39}$ Geralmente, esses problemas envolvem notáveis graus de dificuldade. É verdade que, em larga medida, respostas boas e instrutivas dependem fundamentalmente da adequação do referencial teórico utilizado. No entanto, há resultados bem estabelecidos que são obtidos mediante vários quadros referenciais e por uma multiplicidade enorme de métodos experimentais, circunstância essa que sugere enfaticamente uma inferência em prol da solidez e da objetividade desses resultados. Como exemplos temos, as medidas da carga e da massa do elétron, o número de Avogadro e o caráter esférico (arredondado) da forma geométrica da Terra.
} 
Dito isso, sugerimos que uma aproximação entre a epistemologia complexa de Bachelard e a filosofia de Popper se complemente com a metodologia lakatosiana dos programas de pesquisa científica. Cremos que isso seja importante para a organização do pensamento científico dos dias de hoje.

E para reforçar a importância das idéias de Lakatos aqui referidas podemos lembrar que já em 1923, Guido Castelnuovo também já insistia contra o fatalismo da refutação de apenas um desmentido favorável ou contrário; o texto que a seguir reproduziremos é claro em reivindicar, pelo menos de maneira implícita, que o diálogo teoria experimento constitui-se em algo bem mais complexo do que admitir a redução do empreendimento científico constituído por uma ou mais teorias a apenas uma única prova, qualquer que seja essa prova. Vejamos o texto de Castelnuovo:

"Ma non conviene [...] esagerare il valore di prove, sia favorevoli, sia contrarie. Un secolo fa si soleva affermare che una sola smentita offerta dai fatti bastasse a distruggere una teoria. Oggi la moderna critica scientifica ci impone una maggiore cautela". (CASTELNUOVO, 1923: 122 apud MAMONE CAPRIA, 1999a: 337) ${ }^{40}$.

E ainda há um outro elemento de complexidade que agora faremos menção. A Ciência e sua História - e a física em particular - comporta um grande número de programas de pesquisa em competição: os programas atomistas, os programas da teoria do contínuo, os programas que combinavam idéias desses dois programas citados, o programa pitagórico, o heraclitiano, o parmênidiano, o cartesiano, o leibniziano, o newtoniano, o einsteiniano, o bohriano, ..., e muitos e muitos outros. A história da ciência nos ensina que há muitas contradições, muitas lacunas e enormes desafios em vista da superação dessas contradições. A ciência progride muitíssimo com a competição salutar entre os programas de pesquisa e qualquer análise de longo alcance vai nos mostrar que o pluralismo de métodos e concepções é sempre fértil. Em problemas complexos e recorrentes os termos de "ganhador" ou "perdedor" levariam os "deuses" a gargalhadas. E é também neste sentido que queremos dar sentido à epígrafe de Pascal que escolhemos para o texto deste trabalho.

E no contexto das dificuldades inerentes às idéias, por um lado, de experimentos cruciais e de competição entre programas científicos de pesquisa e, por outro, da complexidade do diálogo teoria/experimento é que deve ser analisado, por exemplo, o intrigante problema da $n$ ão-localidade em mecânica quântica. Diferentemente daqueles que pensam que soluções definitivas já foram dadas, há os mais cautelosos como Penrose. Este último assim se manifestou:

"Schrödinger himself had pointed out, in
1935 (as a follow-up from some work by Einstein, Podolsky and Rosen), the puzzling phenomenon of quantum entanglement, according to which, in a system composed of more than one particle, the individual particles are not actually individual, but must be thought of as constituting an indivisible whole. In the mid-1960s John Bell showed that this entanglement could actually be directly measured, with consequences for our picture of reality that have still, in my opinion not adequately resolved". (PENROSE, 1996 prefácio (foreword) a SCHRÖDINGER) ${ }^{41}$.

Penrose reconhece a grande influência intelectual que Schödinger exerceu sobre ele próprio. Ele conjectura, com base nos trabalhos de Schrödinger (1996) acerca da grande dificuldade do conceito de continuidade e também sobre a profundidade conceitual que o número complexo [aquele da forma $a+b i$, onde $a$ e $b$ são quantidades reais e $i=(-1)^{1 / 2}$ ] enseja na teoria quântica. E tudo isso está em linha de continuidade com os seus argumentos. No mesmo prefácio (foreword) acima referido, Penrose escreve:

“...in my personal view, the more 'objective' philosophical standpoints of Schrödinger and Einstein with respect to quantum mechanics, are immensurably superior to 'subjective' ones of Heisenberg and Bohr". (PENROSE, prefácio a SCHRÖDINGER, 1996) ${ }^{42}$

Encerremos agora o nosso trabalho com algumas palavras sobre a Educação e a Autonomia, temas esses, aliás, que reputamos da mais alta importância e em relação aos quais temos nos empenhado em refletir, em colaboração com alguns de nossos colegas. (MEDEIROS et. al., 1999; AUSTRILINO et al. 2001a, 2001b; BASTOS FILHO, 2001, 2001a, 2001b, 2002) Perguntaríamos então:

Em que medida este nosso estudo pode beneficiar a Educação e o Desenvolvimento dos Indivíduos?

Em que medida a reflexão e o aprofundamento dos problemas da Realidade, da Compreensibilidade e da Causalidade podem nos ajudar nas nossas atividades como cientistas, professores e cidadãos?

Uma das respostas mais diretas, embora seja uma resposta nada trivial, pois se trata de um futuro incerto, seria aceitar o desafio de Kant do Sapere Aude, ou seja, a procura de autonomia tanto daquela de teor político quanto daquela no sentido intelectual propriamente dito. É evidente que ambas as autonomias, política e intelectual, não dispensariam os esforços cooperativos e de sinergia consubstanciados nas relações recíprocas dos indivíduos uns com os outros.

\footnotetext{
40 "Mas não convém [... ] exagerar o valor das provas sejam favoráveis ou sejam contrárias. Há um século se costumava afirmar que apenas um desmentido oferecido pelos fatos era tudo o que bastava para destruir uma teoria. Hoje, a moderna crítica científica nos impõe uma maior cautela.’(CASTELNUOVO, 1923 apud MAMONE CAPRIA 2002a:298)

41 “O próprio Schrödinger fez notar, em 1935 (em continuidade ao trabalho de Einstein, Podolsky e Rosen), o intrigante fenômeno do emaranhado quântico de acordo com o qual em um sistema composto de mais de uma partícula, as partículas individuais não são realmente individuais e assim, devem ser concebidas como um todo indivisível. Em meados dos anos sessenta do século vinte John Bell mostrou que esse emaranhado poderia ser realmente medido, com conseqüências para a nosso quadro de realidade que, no meu modo de entender, não foram adequadamente resolvidas."

42 “....segundo a minha visão pessoal, as concepções filosóficas 'objetivas' de Schrödinger e de Einstein em relação à mecânica quântica, são imensamente superiores às correspondentes concepções 'subjetivas'de Heisenberg e de Bohr."
} 
Realismo para não cairmos na alienação da moda e não passarmos a valorizar em demasia virtualidades e dissoluções hiperbólicas, mas sempre tendo em mente que as idéias são coisas poderosas e que podem nos ajudar a mudar o mundo em que vivemos.

Compreensibilidade para que possamos ver que, apesar de tudo há uma inteligibilidade possível em toda essa loucura.

Causalidade para não abandonarmos um contato com um mundo bem palpável no qual haja sempre uma razão suficiente para as coisas serem assim e não de uma outra maneira, inclusive naquilo que diz respeito ao caos e ao imprevisível.

Quanto ao positivismo e à sua influência deveremos sempre combatê-los, pois o Realismo, a Compreensibilidade genuína e a procura de Causas num mundo indeterminista e sujeito à luta de propensões (BASTOS FILHO \& SELLERI, 1995), assim nos recomenda.

E se pecarmos por exagerado otimismo - o que, aliás, não é um pecado tão grave - é possível mesmo que este estudo sobre alguns dos problemas epistemológicos suscitados pela teoria quântica tenha nos ajudado um pouco nesta direção.

\section{Agradecimentos}

Agradecemos ao Professor Osmar de Souza e Silva Júnior do Departamento de Física da Universidade Federal de Sergipe pelo amável convite para proferirmos a palestra que nos propiciou a oportunidade de escrever este trabalho. Agradecemos ao professor João Zanetic pela conversa informal que nos incentivou a procurar conexões entre tradições culturais diferentes e também ao árbitro deste trabalho pelas relevantes críticas e sugestões.

\section{Referências}

ANGOTTI, J. A. P., 2002, 'Física e Epistemologia Heterodoxas: David Bohm e o Ensino de Ciências', Caderno Brasileiro de Ensino de Física, Vol 19, número especial, pp. 126-156.

AUSTRILINO SILVA, L \& BASTOS FILHO, J. B., 1995, 'Which is the 'true force'? Cartesian Quantity of Motion or Leibniz's Vis Viva?', In: Proceedings of the Third International History, Philosophy and Science Teaching Conference, Minneapolis, Minnesota, Estados Unidos da América, 29 de outubro a $1^{0}$ de novembro de 1995 , pp. 1068-1079.

2001a, 'The Stress

between Neoromantic Reaction and Triumphant Science', Sixty Conference of the International History, Philosophy and Science Teaching Group, Denver, Colorado, Estados Unidos da América, 7-10 de novembro de 2001.

2001b, 'How to Te-

ach Quantum Mechanics?', Sixty Conference of the International History, Philosophy and Science Teaching Group, Denver, Colorado, Estados Unidos da América, 7-10 de novembro de 2001.

BACHELARD, G., 1988, O Novo Espírito Científico, Coleção ‘Os Pensadores', Nova Cultural, São Paulo.

BACON, F., 1988, Novum Organum ou Verdadeiras Indicações acerca da Interpretação da Natureza, In: Coleção 'Os Pensadores', Nova Cultural, São Paulo
BARBOSA FREIRE, M. I. \& BASTOS FILHO, J. B., 1995, 'É possível pensar sem teoria? O que veria um suposto tabula rasa teórico?', Caderno Catarinense de Ensino de Física, Vol. 12, n. 2, pp. 79-94.

BARONE, M. \& SELLERI, F. (ORGS.) 1994, Frontiers of Fundamental Physics, Plenum Press, New York.

BASSALO, J. M. F., 1989, 'A Crônica da Óptica Clássica (Parte III: 1801-1905)', Caderno Catarinense de Ensino de Física, Vol. 6, n. 1, pp. 37-58.

1990, Crônicas da Física, Tomo 2, Editora Universitária da Universidade Federal do Pará (UFPA), Belém, Pará, Brasil.

BASTOS FILHO, J. B., 1986, 'Cartesian and Newtonian Concepts of Mass', American Journal of Physics, Vol. 54, n. 3, pp. 201-202.

1987, 'Comment on letter by Erlichson [Am. J. of P., 104, (1987)]', American Journal of Physics, Vol. 55, n. 11, p. 969.

1994, 'Dangerous effects of the incomprehensibility in microphysics', In: BARONE, M. \& SELLERI, F. (ORGS), 1994, pp. 485-492.

BASTOS FILHO, J. B. \& SELLERI, F, 1995, 'Propensity, Probability and Quantum Physics', Foundations of Physics, Vol. 25, n ${ }^{0}$ 5, pp. 701-716.

BASTOS FILHO, J. B. 1999a, 'La Dissoluzione della Realtà: Irrealismo e Indeterminismo nella Fisica del Microcosmo', In: MARCO MAMONE CAPRIA (ORG.), 1999, pp. 417- 481 [Ver adiante a referência da Edição Brasileira, 2002a].

1999b, 'Descartes, Leibniz, Newton and Modern Physics: Plenum, Action at a Distance and Locality', In: CONTI, L \& MAMONE CAPRIA, M. (ORGS.) 1999.

1999c, O que é uma Teoria Científica?(Uma breve provocação sobre um tema complexo), Editora da Universidade Federal de Alagoas (EDUFAL), $2^{a}$ edição ( a $1^{a}$ edição foi de 1998), Maceió, Alagoas, Brasil. 2000, 'Sobre os Paradigmas de Kuhn, o Problema da Incomensurabilidade e o Confronto com Popper', Acta Scientiarum, Vol. 22, n ${ }^{0} 5$, pp. 1297-1309.

2001, 'A Ciência Normal e a Educação são Tendências Opostas?', In: BURSZTYN, M., 2001 (ORG.), pp. 61-93.

2001a, 'Il Giudizio dei 'pari' e dei 'dis-

pari' ', Convegno Internazionale Scienza e Democrazia, Nápoles, 20-21 de abril de 2001.

2001b, 'A Agenda 21 e a Sociedade Alagoana', In: TONHOLO, J. (ORG.) 2001, pp. 149-175. 2002, 'Cabeça Bem-Feita versus Cabeça Cheia', Pesquisa, ano1, $\mathrm{n}^{0} 1$, p.3 (Revista da FAPEAL/ Fundação de Pesquisa do Estado de Alagoas)

2002a, 'A Dissolução da Realidade: Irrealismo e Indeterminismo na Física do Microcosmo', In: MARCO MAMONE CAPRIA (ORG.), 2002, pp. 369-427. BELL. J. S.. 1990, 'Against Measurements', Physics World, agosto, pp. 33-40.

BOHM, D. \& HILEY, B. J., 1993, The Undivided Universe, Routledge, Londres e New York.

BOHR, N. 1961, Atomic Physics and Human Knowledge, Science Editions, Inc., New York.

BOHR, N., 2000, 'O Postulado Quântico e o Recente Desenvolvimento da Teoria Atômica' In: PESSOA JR., O. (Ed.), 
Fundamentos da Física I - Simpósio David Bohm, Livraria da Física, São Paulo, pp. 135-159.

BORN, M., 1969, Physics in my Generation, Springer, New York.

BOTHE, W. \& GEIGER, H., 1925, 'Über das Wesen des Comptoeffektes; ein experimenteller Beitrag zur Theorie der Strahlung', Zeitschrift für Physik, Vol. 32, p.639.

BURSZTYN, M., 2001 (ORG.), Ciência, Ética e Sustentabilidade, Cortez Editora, UNESCO, CDS/UnB, São Paulo, Brasília.

CARR, E. H., 1989, Que é História?, Editora Paz e Terra, $6^{a}$ edição, Rio de Janeiro, Brasil.

CARUSO, F. \& MOREIRA XAVIER R, 1994, 'Causa formalis versus causa efficiens: origem da discussão moderna sobre a dimensionalidade do espaço físico', Cadernos de História e Filosofia da Ciência, Série 3, Vol 4. pp. 41-62, Campinas.

CASTELNUOVO, G. 1923, Spazio e Tempo secondo le vedute di A. Einstein, Zanichelli, Bolonha, Itália.

CHALMERS, A. F., 1999, O que é Ciência Afinal?, Editora Brasiliense, (primeira edição, terceira reimpresão), São Paulo.

COMPTON, A. H.. \& SIMON, A. W.,1925a, 'Measurements of $\beta$-rays associated with scattered $x$-rays', Physical Review, Vol. 25, pp. 306-313.

1925b, 'Directed quanta of scattered $x$-rays', Physical Review, Vol. 26, pp. 289-299.

COMTE, A., 1988, Curso de Filosofia Positiva, In: Coleção 'Os Pensadores', Nova Cultural, São Paulo.

CONTI, L. \& MAMONE CAPRIA, M. (ORGS) 1999, La Scienza e $i$ Vortici del Dubbio, Edizioni Scientifiche Italiane, Nápoles, Itália.

DUHEM, P., 1914, La Théorie Physique. Son object sa structure [originalmente publicado em 1906], $2^{a}$ edição, Vrin 1989, Paris.

EINSTEIN, A., 1993, Letters to Solovine (1906-1955), Citadel Press, New York.

FERRATER MORA, J., 1975, Diccionario de Filosofia, $\left(3^{a}\right.$ reimpressão da $5^{a}$ edição, em dois volumes) Editorial Sudamericana, Buenos Aires.

FEYNMAN, R. P., 1965, Lectures on Physics, Vol 3, Addison-Wesley, Reading, Massachusetts.

FIREMAN, E. C. \& BASTOS FILHO, J. B., 1998, 'Sobre um Modelo que reproduz a Teoria Quântica de Spin 1/2', Revista Brasileira de Ensino de Física, Vol. 20, $\mathrm{n}^{0}$ 2, pp. 122-132.

FIZEAU, A. H. L. \& BREGUET, L., 1850, Comp. Rend. 30: 562-771.

FORMAN, P., 1971, ' Weimar Culture, Causality and Quantum Theory (1918-1927): Adaptation by German Physicists and Mathematicians to a Hostile Environment', Historical Studies in the Physical Sciences, vol. 3, pp. 1-115.

1983, 'A Cultura de Weimar, a Causalidade e a Teoria Quântica, 1918-1927', Cadernos de História e Filosofia da Ciência, suplemento 2, Centro de Lógica, Epistemologia e História da Ciência, Unicamp, Campinas (Esta é a tradução em português da referência anterior).

FOUCAULT, J. B. L., 1850 Comp. Rend. 30: 551.

FREIRE JR., O \& PATY, M. \& BARROS, A. L. R, 1994, 'David Bohm, sua Estada no Brasil e a Teoria Quântica', Estudos Avançados, Vol. 20, pp. 53-82.
FREIRE JR, O, 1999, David Bohm e a Controvérsia dos Quanta, Centro de Lógica e Epistemologia da Unicamp (CLE/UNICAMP).

GELL-MANN, M., 1979, In: 'The Nature of Physical Universe' (The 1976(?) Nobel Conference), Wiley, New York. [OBS. : Esta referência apud STAPP, 1987, parece conter um erro o qual não foi possível dirimir. A data de 1976 não corresponde ao ano em que Gell-Mann foi agraciado pelo Prêmio Nobel de Física. Gell-Mann recebeu o prêmio em1969].

HEISENBERG, W., 1983, Encounters with Einstein, and Other Essays on People, Places and Particles, Princeton University Press, Princeton, New Jersey.

HILEY, B. J. \& DAVID PEAT, F. (ORGS.), 1987, Quantum Implications (Essays in Honour of David Bohm), Routledge \& Kegan Paul Ltda, Londres, New York.

HUME, D., 1989, Investigação acerca do Entendimento Humano, In: Coleção 'Os Pensadores', Volume Berkeley/Hume, Nova Cultural, São Paulo.

KLINE, M., 1980, Mathematics. The Loss of Certainty, Oxford University Press, Oxford, New York.

1985, Mathematics and the Search for Knowledge, Oxford University Press, Oxford, New York.

KLIMKE. F., 1947, Historia de la Filosofía, Editorial Labor S. A., Barcelona, Madrid, Buenos Aires, Rio de Janeiro.

KUHN. T. S., 1975, A Estrutura das Revoluções Científicas, Editora Perspectiva, São Paulo.

KUHN, T. S., 1996, The Structure of Scientific Revolutions, ( $3^{a}$ edição), The University of Chicago Press, Chicago, Londres.

LAKATOS, I., 1979, 'O Falseamento e a Metodologia dos Programas de Pesquisa', In: LAKATOS, I. \& MUSGRAVE, A (ORGS.) 1979, pp. 109-243.

LAKATOS, I. \& MUSGRAVE, A. (ORGS.) 1979, A Crítica e o Desenvolvimento do Conhecimento, Editora Cultrix, Editora da Universidade de São Paulo, São Paulo.

LEIBNIZ, G. W., 1988, Correspondência com Clarke, Coleção 'Os Pensadores', Leibniz, Vol. II, Nova Cultural, São Paulo.

LINDLEY, D., 1993, The End of Physics ( The Mith of a Unified Theory), Basic Books, A Division of Harper Collins Publishers, New York.

MAMONE CAPRIA, M., (ORG.) 1999, La Costruzione dell'Immagine Scientifica del Mondo (Mutamenti nella concezione dell'uomo e del cosmo dalla scoperta dell'America alla meccanica quantistica, (Istituto Italiano per gli Studi Filosofici), La Città del Sole, Nápoles, Itália. [Ver mais adiante a referência da Edição Brasileira, 2002]. 1999a, 'La Crisi della Concezioni Ordinarie di Spazio e di Tempo: La Teoria della Relatività', In: MAMONE CAPRIA, M. (ORG.) 1999, pp. 265-416. 1999b, 'Introduzione: La Scienza e l'Immagine del Mondo', In: MAMONE CAPRIA, M. (ORG.), 1999, pp. 11-54.

(ORG.) 2002, A Construção da Imagem do Mundo (As Mutações nas Concepções do Homem e do Cosmos desde o Descobrimento da América até a Mecânica Quântica, Editora da Universidade do Vale do Rio dos Sinos, UNISINOS, São Leopoldo, Rio Grande do Sul, Brasil. 2002a, 'A Crise das Concepções Ordinárias de Espaço e Tempo: A Teoria da Relatividade', In: MAMONE CAPRIA (ORG.) 2002, pp. 231-368. 
2002b, 'Introdução: A Ciência e a Imagem do Mundo', In: MAMONE CAPRIA (ORG.) 2002, pp. 13-50.

MARÍAS, J., 1974, História de la Filosofia, $24^{a}$ edição $\left[1^{a}\right.$ edição de 1941], Revista de Occidente, Madrid.

MEDEIROS, E. \& BASTOS FILHO J. B., 1999, 'O que é Autonomia? (Esboço para um Programa de Reflexão)', Maçeió, Ano 1, $\mathrm{n}^{0}$ 1, Maceió, pp. 31-40.

MORIN, E., 2001, A Cabeça Bem-Feita (Repensar a Reforma, Reformar o Pensamento) Bertrand, Rio de Janeiro, Brasil.

PAIS, A., 1995, “Sutil é o Senhor...”: A Ciência e a Vida de Albert Einstein, Editora Nova Fronteira, Rio de Janeiro.

PASCAL, B. , 1948, Pensées, (Texto da Edição Brunschvicg), Librairie Garnier Frère, Paris. 1988, Pensamentos, Coleção 'Os Pensadores', Nova Cultural, São Paulo.

PENROSE, R., 1996, Prefácio (Foreword) a SCHRÖDINGER, E., 1996.

POPPER, K. R., 1979, 'A Ciência Normal e seus Perigos', In: LAKATOS, I. \& MUSGRAVE, A. (ORGS.), pp. 63-71. 1982, Conjecturas e Refutações, Editora da Universidade de Brasília, Brasília. 1986, (Prefácio a SELLERI, 1986). 2001, Tutta la Vita è Risolvere Problemi, Bompiani, Il Pensiero Occidentale, (Edição bilingüe em italiano e em alemão), Milão, Itália.

RICIERI, A. P., 1988, A Vinda de Einstein ao Brasil, Edições Prandiano, São Paulo.

SCHRÖDINGER, E., 1996, Nature and the Greeks \& Science and Humanism, Canto Edition, Cambridge University Press.

SELLERI, F., 1986, Le Grand Débat de la Théorie Quantique, Flammarion, Paris. 1990, Quantum Paradoxes and Quantum Reality, Vol. 35 da Coleção 'Fundamental Theories in Physics', ORG. por ALWIN VAN DER MERWE, Kluwer Academic Publishers, Dordrecht. 2001, Le Forme della Energia (La Luce e il Calore. $D a E=m c^{2}$ all'energia nucleare), Edizioni Dedalo, Bari, Itália.

STAPP, H. P., 1987, 'Light as Foundation of Being', In: HILEY, B. J. \& DAVID PEAT, F. (ORGS.) 1987, pp. 255-266. TONHOLO, J., (ORG.) 2001, Gestão em Ciência e Tecnologia (Textos Alagoanos), EDUFAL (Editora da Universidade Federal de Alagoas), Maceió, Alagoas, Brasil.

VINTI, C., 1999, 'L'epistemologia non-cartesiana di Bachelard', In: CONTI, L. \& MAMONE CAPRIA, M. 1999 (ORGS.), pp. 151- 165.

WEINBERG, S., 1994, Dreams of a Final Theory (The Scientist's Search for the Ultimate Laws of Nature), Vintage Books, New York. 